\title{
Genes and variants in hematopoiesis-related pathways are associated with gemcitabine/carboplatin-induced thrombocytopenia
}

Niclas Björn, Benjamín Sigurgeirsson, Anna Svedberg, Sailendra Pradhananga, Eva Brandén, Hirsh Koyi, Rolf Lewensohn, Luigi de Petris, Maria Apellániz-Ruiz, Cristina Rodríguez-Antona, Joakim Lundeberg and Henrik Gréen

The self-archived postprint version of this journal article is available at Linköping University Institutional Repository (DiVA):

http://urn.kb.se/resolve?urn=urn:nbn:se:liu:diva-162137

N.B.: When citing this work, cite the original publication.

The original publication is available at www.springerlink.com:

Björn, N., Sigurgeirsson, B., Svedberg, A., Pradhananga, S., Brandén, E., Koyi, H., Lewensohn, R., de Petris, L., Apellániz-Ruiz, M., Rodríguez-Antona, C., Lundeberg, J., Gréen, H., (2019), Genes and variants in hematopoiesis-related pathways are associated with gemcitabine/carboplatin-induced thrombocytopenia, The

Pharmacogenomics Journal. https://doi.org/10.1038/s41397-019-0099-8

Original publication available at:

https://doi.org/10.1038/s41397-019-0099-8

Copyright: Springer Nature [academic journals on nature.com] (Hybrid Journals)

https://www.nature.com/ 


\section{Genes and variants in hematopoiesis-related pathways are associated with gemcitabine/carboplatin-induced thrombocytopenia}

Niclas Björn ${ }^{1}$, Benjamín Sigurgeirsson ${ }^{2,3}$, Anna Svedberg ${ }^{1}$, Sailendra Pradhananga ${ }^{2}$, Eva Brandén ${ }^{4,5}$, Hirsh Koyi $^{4,5}$, Rolf Lewensohn ${ }^{6}$, Luigi De Petris ${ }^{6}$, Maria Apellániz-Ruiz ${ }^{7}$, Cristina Rodríguez-Antona ${ }^{7}$, Joakim Lundeberg $^{2, \&}$ and Henrik Gréen ${ }^{1,2,8, \&, *}$

${ }^{1}$ Clinical Pharmacology, Division of Drug Research, Department of Medical and Health Sciences, Linköping University, Linköping, Sweden. ${ }^{2}$ Science for Life Laboratory, School of Engineering Sciences in Chemistry, Biotechnology and Health, Division of Gene Technology, KTH Royal Institute of Technology, Solna, Sweden. ${ }^{3}$ School of Engineering and Natural Sciences, University of Iceland, Reykjavík, Iceland ${ }^{4}$ Department of Respiratory Medicine, Gävle Hospital, Gävle, Sweden. ${ }^{5}$ Centre for Research and Development, Uppsala University/Region Gävleborg, Gävle, Sweden. ${ }^{6}$ Thoracic Oncology Unit, Tema Cancer, Karolinska University Hospital, and Department of Oncology-Pathology, Karolinska Institutet, Stockholm, Sweden. ${ }^{7}$ Hereditary Endocrine Cancer Group, Spanish National Cancer Research Centre (CNIO), Madrid, Spain. ${ }^{8}$ Department of Forensic Genetics and Forensic Toxicology, National Board of Forensic Medicine, Linköping, Sweden.

\& JL and HG share the last authorship.

* Corresponding author: Henrik Gréen, Clinical Pharmacology, Division of Drug Research, Department of Medical and Health Sciences, Linköping University, SE-58185 Linköping, Sweden.

E-mail: henrik.green@liu.se, Telephone: +46101031544, Fax: +4613104195

Running title: Genetics and chemotherapy-induced thrombocytopenia

\section{Abstract}

Chemotherapy-induced myelosuppression, including thrombocytopenia, is a recurrent problem during cancer treatments that may require dose alterations or cessations that could affect the anti-tumor effect of the treatment. To identify genetic markers associated with treatment-induced thrombocytopenia, we whole-exome sequenced 215 non-small cell lung cancer patients homogeneously treated with gemcitabine/carboplatin. The decrease in platelets (defined as nadir/baseline) was used to assess treatment-induced thrombocytopenia. Association between germline genetic variants and thrombocytopenia was analyzed at single-nucleotide variant (SNV) (based on the optimal false discovery rate, the severity of predicted consequence, and effect), gene, and pathway levels. These analyses identified $130 \mathrm{SNVs}$ and 25 genes associated with thrombocytopenia ( $P$-value<0.002). 23 SNVs were validated in an independent genome-wide association study (GWAS). The top associations include rs34491125 in JMJD1C (P-value $\left.=9.07 \times 10^{-5}\right)$, the validated variants rs10491684 in DOCK8 (Pvalue $\left.=1.95 \times 10^{-4}\right)$, rs6118 in SERPINA5 $\left(\mathrm{P}\right.$-value $\left.=5.83 \times 10^{-4}\right)$ and rs5877 in SERPINC1 (P-value $\left.=1.07 \times 10^{-3}\right)$, and the genes CAPZA2 ( $\mathrm{P}$-value $\left.=4.03 \times 10^{-4}\right)$ and SERPINC1 $\left(\mathrm{P}\right.$-value $\left.=1.55 \times 10^{-3}\right)$. The SNVs in the topscoring pathway "Factors involved in megakaryocyte development and platelet production" (Pvalue $=3.34 \times 10^{-4}$ ) were used to construct weighted genetic risk scores (wGRS) and logistic regression models that predict thrombocytopenia. The WGRS predict which patients are at high or low toxicity risk levels, for CTCAE $\left(\mathrm{OR}=22.35\right.$, $\mathrm{P}$-value $\left.=1.55 \times 10^{-8}\right)$, and decrease $\left(\mathrm{OR}=66.82, \mathrm{P}\right.$-value $\left.=5.92 \times 10^{-9}\right)$. The logistic regression models predict CTCAE grades 3-4 (receiver operator characteristics $(\mathrm{ROC})$ area under the curve $(A \cup C)=0.79)$, and large decrease $(R O C A \cup C=0.86)$. We identified and validated genetic variations within hematopoiesis-related pathways that provide a solid foundation for future studies using genetic markers for predicting chemotherapy-induced thrombocytopenia and personalizing treatments. 


\section{Introduction}

Lung cancer is both common and lethal. It represents $13 \%$ of all newfound cancer cases, causes $19 \%$ of all cancer-related deaths, and has a 5 -year survival of only $18 \% .{ }^{1,2}$ Classical chemotherapeutic treatment of non-small cell lung cancer (NSCLC) commonly consists of gemcitabine and carboplatin, depending on the result of the primary treatment using either PD-1 inhibitors or targeted therapies. The regime is known to cause severe toxicity that may require postponement or reduction of the treatment dose and, in some cases, even discontinuation of the therapy. Myelosuppression is the most commonly induced adverse drug reaction (ADR), manifesting itself as anemia, leukopenia, neutropenia, and thrombocytopenia. ${ }^{3,4}$ Severe thrombocytopenia of Common Terminology Criteria for Adverse Events (CTCAE) grade 3-4 is commonly observed in patients in clinical studies, ${ }^{5-10}$ in most cases, reported in 50$70 \%$ of the patients. There is a vast inter-individual variability in thrombocytopenia, and with equal doses, some patients exhibit no or mild symptoms, while others experience severe thrombocytopenia even after the first course of treatment.

The underlying mechanisms for induced ADRs in patients treated with chemotherapy are, to date, not fully understood for myelosuppression or thrombocytopenia. Germline genetic variability is thought to affect toxicity, and efforts have been made to find ways to predict myelosuppression in chemotherapy treatments by using candidate gene approaches and genome-wide association studies (GWAS). ${ }^{10-16}$ These previous studies, mostly of Asian origin, have investigated either a single treatment regimen in patients with various tumor types or multiple treatment regimens in patients with a single tumor type.

Being able to predict patient risk of thrombocytopenia, and adjust doses and treatments accordingly, would most likely be beneficial for both patient quality of life and response to treatment, and it would reduce hospitalization times and costs related to treatment-induced toxicity.

The purpose of this study was, therefore, to identify the genes and variants underlying the interindividual variability in gemcitabine/carboplatin-induced thrombocytopenia, with the goal of identifying genetic variations that can be used for the prediction of toxicity. To do this, we conducted whole-exome sequencing of NSCLC patients homogeneously treated with gemcitabine/carboplatin chemotherapy using high-throughput next-generation sequencing. We, subsequently, performed association analyses of thrombocytopenia at the single nucleotide variant (SNV), gene, and pathway levels and validated the results in an independent patient cohort.

\section{Materials and Methods}

\section{Study population}

Between 2006 and 2008, 215 NSCLC patients at Karolinska University Hospital, Stockholm, Sweden, were included in the study. The regional ethics committee in Stockholm, Sweden, approved the study (DNR-03-413 with amendment 2016/258-32/1), and all patients provided written and oral informed consent as per the Declaration of Helsinki. A subsample of these patients had previously been included in another toxicity study of 32 patients. ${ }^{10}$ The 215 participants received at least one cycle of carboplatin (area under the curve (AUC) $=5$, at day 1 ) and gemcitabine $\left(1250 \mathrm{mgm}^{-2}\right.$ at day 1 and day 8$)$, which was the standard of care for NSCLC patients at the time and place of the study. Platelet counts were registered at baseline and monitored at day 8,15 , and 21 during the first cycle. The platelet nadir value and the decrease in platelets (defined in Equation 1 ) were used as toxicity parameters for thrombocytopenia.

$$
\text { Equation 1: } \quad \text { decrease }=\text { nadir } / \text { baseline }
$$




\section{DNA extraction, exome enrichment, and sequencing}

DNA was extracted from whole blood using QIAamp DNA mini-kits (VWR International, Stockholm, Sweden) according to the manufacturer's protocol. Target enrichment and library preparation were performed using the Nextera Rapid Capture Exome kit (FC-140-1003, Illumina, San Diego, California, USA) according to the manufacturer's instructions and utilizing Agilent Bravo for automation. All samples were whole-exome sequenced on Illumina HiSeq 2500 v4 (generating 125 base-pair long paired-end reads) at the Science for Life Laboratory, Stockholm, Sweden.

\section{Quality control, alignment, and variant calling}

Sequencing reads were quality and adapter trimmed using TrimGalore! (http:// www.bioinformatics.babraham.ac.uk/projects/trim galore/) and cutadapt. ${ }^{17}$ Trimmed reads with a Phred quality score $<25$ and read-pairs with one read length $<25$ were removed. Alignment to the human genome (GRCh37.72, http://www.ensembl.org/) was done using Bowtie2. ${ }^{18}$ Mapped reads were filtered, using SAMtools, ${ }^{19}$ to only utilize primary aligned reads that mapped in proper pairs. Duplicate reads were discarded using Picard Tools (http://www.picard.sourceforge.net/). Variant calling was conducted using the Genome Analysis Toolkit (GATK) version 3.1.1. supplied with the Nextera Rapid Capture Exome Targeted Regions Manifest version 1.2 and following their best practice pipeline. ${ }^{20}$

\section{Post-variant calling quality control and outlier removal}

VCFtools ${ }^{21}$ was used to discard variants not labeled as PASS, with genotyping rate $<0.95$, with mean coverage $<10$ across all samples, and that failed the Hardy-Weinberg test with a P-value of 0.0001 . Detection of outliers was conducted using the metrics identity by descent (IBD) and identity by missingness (IBM) in PLINK. ${ }^{22}$ Three samples were identified as outliers, see Supplementary Figure S1, and deemed to be unreliable and, consequently, were removed from all subsequent analyses.

\section{Association analysis}

\section{Phenotype values and transformations}

The two toxicity parameters of thrombocytopenia, nadir values and the decrease in the nadir values, were normalized using the natural logarithmic transformation in $\mathrm{R}$ version $3.4 .1^{23}$ and a rank-based transformation using van der Waerden normal scores implemented in the tRank function in the Rpackage multic. Supplementary Figure S2 shows the distribution before and after the transformation of nadir values and the decrease. The transformation gave four normal-distributed phenotype values (PVs) for thrombocytopenia that were used for the association analyses: the natural logarithm transformation of nadir values (PV1) and the decrease (PV2), and the rank-based transformation of nadir values (PV3) and the decrease (PV4).

\section{SNV association analysis}

Common variants (minor allele frequency $(M A F) \geq 0.01$ ) were included in the SNV association analyses that were carried out individually for the four PVs of thrombocytopenia using an additive genetic model in PLINK ${ }^{22}$ with the covariates age and gender. To evaluate the different PVs and a to estimate a suitable P-value cut-off, 1000 permutations with randomly shuffled PVs were performed. Supplementary Figure S3 contains the results of the permutation tests. It is evident from the results that the decrease parameters PV2 and PV4 had an optimal P-value cut-off of $\leq 0.002$, which was determined to yield the largest difference from the random permutations with the lowest false discovery rate (FDR). The results also show that the nadir values in PV1 and PV3 reflect the random effect and, therefore, these values were not investigated further. All SNVs from the PV2 and PV4 analyses were scored using Combined Annotation-Dependent Depletion (CADD), ${ }^{24}$ a method that integrates various annotations into a single score for each variant. 


\section{Gene-based association analysis}

The combined effect of common $(\mathrm{MAF} \geq 0.01)$ and rare $(\mathrm{MAF}<0.01)$ genetic variants within a gene region (exon region in RefSeq GRCh37/hg19 \pm 6 base pairs) on thrombocytopenia was evaluated with the optimal sequence kernel association test in the R-package SKAT ${ }^{25}$ using default settings, assigning equal weight to all variants, and with age and gender as covariates. Genes harboring only one genetic variant were excluded.

\section{Potentially pertinent variants and genes}

We used a stringent requirement that SNVs and genes had to surpass the P-value cut-off $<0.002$ for both PV2 and PV4 as a measure to reduce the likelihood of false positives. SNVs and genes that met this requirement were considered to infer association and were denoted as potentially pertinent variants (PPVs) and potentially pertinent genes (PPGs).

\section{Validation}

\section{Validation cohort}

As a validation, SNVs with MAF $\geq 0.01$ and a P-value $<0.002$ for the association to thrombocytopenia ( $n$ = 1595) from an independent GWAS generated in ${ }^{26}$ (briefly described in Supplementary Material S1 and accompanied with information on the successfully validated variants in Supplementary Table S1) were used.

\section{Validation method}

Linkage disequilibrium (LD) between SNVs from the validation cohort and our PPVs was examined using the EnsembI REST API (version 6.3). Pair-wise LD was evaluated for variant pairs closer than 500 kilobases using the European population panels CEU (Utah residents with Northern and Western European ancestry), FIN (Finnish in Finland), GBR (British in England and Scotland), IBS (Iberian populations in Spain) and TSI (Toscani in Italia) from the 1000 Genomes Phase 3 data. A D' > 0.33 was considered to indicate $L^{27}$ and validate the possible importance of the genetic variants for treatmentinduced thrombocytopenia.

\section{Pathway analysis}

Over-representation analysis of pathway-based sets was performed using the online tool ConsensusPathDB-human (Release 33, http://cpdb.molgen.mpg.de/) ${ }^{28}$ to find genes enriched in predefined pathways in the ConsensusPathDB-human meta-database containing data from various heterogeneous resources. The tool was supplied with all unique genes represented by PPGs, validated PPVs, or PPVs with a CADD $>20$. The over-representation analysis used the default settings, which consisted of a minimum two-gene overlap and a P-value $<0.01$.

\section{Weighted genetic risk score (wGRS) for thrombocytopenia}

We constructed weighted genetic risk scores (wGRS) using the SNVs represented in the top associated pathway to predict the risk of thrombocytopenia in our patients. Beta values for the minor alleles acquired in the SNV association analyses were used as weights for the included SNVs. The wGRS were created by multiplying the beta values by the number of minor alleles $(0,1$, or 2$)$ summarized across all model SNVs for each patient. The patients were split into four toxicity risk levels (low, medium-low, medium-high, and high) based on the quantiles of the wGRS. The toxicity risk levels were then plotted against thrombocytopenia as CTCAE grades $0-2$ and 3-4 or as the magnitude of the decrease in platelets (small decrease: $\geq 25 \%$, medium decrease: $25-10 \%$, or large decease: $\leq 10 \%$ ). Differences in the distribution of thrombocytopenia between the toxicity risk levels were assessed using two-sided Fisher's exact test in $\mathrm{R}$ version 3.4.1. ${ }^{23}$ 


\section{Logistic regression model for thrombocytopenia}

Using the SNVs represented in the top associated pathway two separate binomial logistic regression models were constructed, one for CTCAE grades 0-2 versus 3-4, and one for a small decrease versus a large decease in platelets (as defined in the previous section), using the function $\mathrm{glm}$ in $\mathrm{R}$ version 3.4.1. ${ }^{23}$ The predictive capacity of the models were evaluated with receiver operating characteristics (ROC) and AUC using the R-package ROCR version 1.0-7. ${ }^{29}$

\section{Results}

\section{Patient characteristics}

The patient characteristics and thrombocytopenia graded according to the National Cancer Institute's CTCAE (version 4.03) are presented in Table 1. The gender of the patients from the clinical report forms was confirmed genetically using check sex in PLINK. ${ }^{22}$

\section{Exome target enrichment, sequencing, and variant calling}

The average number of paired reads from the sequencing was 38.7 million. The average mapping yield was $99.2 \%$, and the average exome coverage was $74 \mathrm{X}$. There were about 28000 non-reference variants per sample, and a total of 148148 variants were identified, of which 71374 were common (MAF $\geq 0.01$ ).

\section{Association analysis}

\section{SNV association analysis}

The SNV association analysis identified a total of 130 PPVs (SNVs with P-values $<0.002$ for both PV2 and PV4) associated with thrombocytopenia. Detailed information on all the PPVs is listed in Supplementary Table S2. Of the PPVs, 97 had negative beta values, meaning that the minor allele is associated with higher toxicity. Interestingly, 50 of the associated variants resided on chromosome 6 . In total, the PPVs were represented by 103 unique genes. Of all PPVs, 11 had CADD scores above $>20$, indicating that they can be predicted to be among the top $1 \%$ most deleterious variants in the human genome. Of these 11 variants, rs6907580 (minimal P-value $=6.41 \times 10^{-4}, C A D D=35.00$ ), a stop-gain variant in GPRC6A, and rs34491125 (minimal P-value $=9.07 \times 10^{-5}, C A D D=22.10$ ), a missense variant in JMJD1C, represent the variants with the highest CADD score and the lowest $P$-value, respectively.

\section{Gene-based association analysis}

The gene-based analysis associated 25 PPGs (genes with P-values $<0.002$ for both PV2 and PV4) with thrombocytopenia, listed in Supplementary Table S3. Of the PPGs, 18 were also represented by PPVs in the same genes, of which CHM, OR2B2, and PPP1R18 included the top CADD scoring variants.

\section{Validation}

By using the 1595 SNVs in the validation data, we found 112 pairs of PPVs and SNVs that were within 500 kilobases of each other. LD data from the European populations in 1000 Genomes Phase 3 data was available for 48 of these pairs (note that European LD data is missing for the remaining 64 pairs). The 48 pairs represented 23 unique PPVs that could be validated, meaning that the validation SNVs and PPVs indicated an LD with $D^{\prime}>0.33$. All validated PPVs and their corresponding validation SNV (or SNVs, as some PPVs were validated by multiple variants) are listed in Table 2 . The validated PPVs with the two highest CADD scores were rs6118 (missense, minimal P-value $=5.83 \times 10^{-4}, \mathrm{CADD}=22.30$ ), validated by rs3790036 (Hazard ratio $(H R)=1.91$ ), and rs10491684 (synonymous, minimal P-value $=1.95 \times 10^{-4}$, CADD $=11.71)$, validated by rs7025610 (HR = 2.35), located in SERPINA5 and DOCK8, respectively. Further, the three PPGs, CYP2C8, PPP1R18, and SERPINC1 also included validated variants 


\section{Pathway analysis}

The pathway analysis used 45 genes as input (all unique genes represented by PPGs, validated PPVs or PPVs with a CADD > 20) and identified 14 enriched pathways, listed in Table 3. Of the pathways, two were considered very relevant for the investigated phenotype, gemcitabine/carboplatin-induced thrombocytopenia. These two were also the pathways with the lowest associated P-values. They are briefly presented here. The "Hemostasis" pathway $\left(\mathrm{P}\right.$-value $\left.=1.27 \times 10^{-3}\right)$ was identified to be enriched via the association to thrombocytopenia of seven genes; CAPZA2, DGKD, DOCK8, JMJD1C, KIF6, SERPINA5, and SERPINC1. Even more interesting, a subpathway to "Hemostasis" called "Factors involved in megakaryocyte development and platelet production" (P-value $\left.=3.34 \times 10^{-4}\right)$ was enriched via the genes CAPZA2, DOCK8, KIF6, and JMJD1C. These genes included genetic variants with high CADD scores (among the variants in Supplementary Table S2), validated variants (Table 2), and genes from the genebased association analysis (Supplementary Table S3).

\section{Risk prediction of thrombocytopenia wGRS}

Next, we constructed wGRSs for each patient using the 17 SNVs covered by the genes CAPZA2, DOCK8, KIF6, and JMJD1C represented in the pathway "Factors involved in megakaryocyte development and platelet production". Supplementary Table S4 lists the 17 SNVs together with the beta values and the minor alleles used for calculating the wGRS. The patients were split into the toxicity risk levels low, medium-low, medium-high, and high based on the quantiles of the wGRS. Figure 1A shows the distribution of CTCAE grades $0-2$ and 3-4 in the toxicity risk levels, and Figure 1B shows the distribution of the magnitude of decrease in the toxicity risk levels. Fisher's exact test showed that the wGRS can classify patients accurately to low and high toxicity risk levels (Table 4). Patients in the high toxicity risk level are more likely than patients in the low toxicity risk level to experience CTCAE grades 3-4 (odds ratio $(O R)=22.35$, P-value $\left.=1.55 \times 10^{-8}\right)$ or a large decrease to $\leq 10 \%$ of the baseline value $(\mathrm{OR}=66.82, \mathrm{P}$ value $\left.=5.92 \times 10^{-9}\right)$. This indicates that these $17 \mathrm{SNVs}$ can be used in wGRS models to predict risk of severe thrombocytopenia, although further validation is needed.

\section{Logistic regression}

Using the same 17 SNVs, as for the wGRSs above, logistic regression models for predicting CTCAE grades 3-4 and a large decrease of platelets were implemented. Figure 2A shows the thrombocytopenia CTCAE model predictions of CTCAE grades $3-4$ and Figure $2 B$ shows the associated ROC curve (AUC $=0.79$ ). The decrease model predictions of large decrease are shown in Figure $2 \mathrm{C}$ and the associated ROC curve (AUC $=0.86$ ) is shown in Figure 2D. The coefficients that were used in the two logistic regression models, determined by the function glm, are listed in Supplementary Table S5.

\section{Overview}

An overview of the statistical approach and the most relevant associated pathways for gemcitabine/carboplatin-induced thrombocytopenia are shown in Figure 3. It can be seen how the results come together in pathways that include genes and SNVs consistent over many analyses that were partly validated and of high CADD scores. These results indicate that SNVs can be used for risk prediction of thrombocytopenia.

\section{Discussion}

In this study, exome variants from 212 (after quality control) NSCLC patients undergoing gemcitabine/carboplatin treatment were analyzed for genetic association with chemotherapy-induced thrombocytopenia. The main strengths of the study are the uniform NSCLC patient population, the use 
of a single treatment regimen of gemcitabine/carboplatin, and the sample size, which, to the best of our knowledge, is the most extensive study using whole-exome sequencing to investigate drug-induced thrombocytopenia as its primary outcome.

The study found 130 SNVs, of which 23 were validated (43\% of those that could be validated), 25 genes, and 14 enriched pathways associated with thrombocytopenia. By using the analysis strategy presented, we could concentrate on the associations consistent over many analyses that were validated, and that were in pathways relevant to the investigated phenotype thrombocytopenia (for an overview see Figure 3). These results could be used to construct wGRS models and logistic regression models that can predict patients risk and probability of CTCAE grades 3-4 and a large decrease in platelets. However, other individual SNV, genes, and pathways could be pertinent to treatment-induced thrombocytopenia, therefore, all PPVs, PPGs, and pathways are reported in the associated supplements.

Many associations on chromosome 6 ( 50 SNVs, 14 genes and 13 validated variants) were found. These included the gene PPRP18 with the validated high CADD scoring (32.00) variant rs9262143, and the gene KIF6, which is among the genes in the relevant pathways. This finding suggests the importance of genetic regions on chromosome 6 for thrombocytopenia.

The primary findings of the study are the enriched pathways that clearly anchor back to thrombocytopenia. First, the broad "Hemostasis" pathway in which we found associations to thrombocytopenia for the following genes CAPZA2, DGKD, DOCK8, JMJD1C, KIF6, SERPINA, and SERPINC1, which are all potentially interesting for further investigation. The variant rs6118 in SERPINA5 had a high CADD score (22.30) and was validated in the GWAS dataset, which added to its relevance. SERPINC1 was associated through five variants in the gene-based analysis, of which rs5877 is a synonymous variant that was also among the validated PPVs found. SERPINC1 deficiency is known to cause thrombophilia, ${ }^{30,31}$ a condition in which blood has an increased tendency to form clots, which indicates that the gene has major effects in the body. This indicates that variation in or near SERPINC1 could also affect thrombocytopenia. The four genes JMJD1C, CAPZA2, DOCK8, and KIF6 in the "Hemostasis" pathway are of particular interest as they are all also involved in the top enriched pathway "Factors involved in megakaryocyte development and platelet production". This pathway seems to be highly involved in the thrombocytopenia investigated in this study. It included the PPV rs34491125 in $J M J D 1 C$ a missense variant with a high CADD score (22.10), indicating a deleterious effect. The gene $J M J D 1 C$ is known to have a function in the formation of platelets, both in model organisms and in humans. In zebrafish, silencing JMJD1C leads to failed erythropoiesis and thrombopoiesis, and in humans, the variants rs10761731 and rs7075195 in JMJD1C have been correlated to platelet count and mean platelet volume, respectively. ${ }^{32}$ The mean platelet volume has previously been correlated to the $J M J D 1 C$ variants rs $10761741^{33}$ and $\mathrm{rs} 4379723 .{ }^{34}$ Interestingly, after assessing the pairwise LD (using the same approach as in the validation process) of these four SNVs and the PPV rs34491125 in JMJD1C, we found that $r s 34491125$ is in LD with $r$ 10761731 $\left(r^{2}=0.05, D^{\prime}=1.00\right.$, CEU), rs7075195 $\left(r^{2}=0.05, D^{\prime}=\right.$ $1.00, C E U)$, and $r s 10761741\left(r^{2}=0.05, D^{\prime}=1.00, C E U\right)$, however, no European LD data was available for rs4379723. The region around and including JMJD1C has also been reported in relation to mean platelet volume..$^{35}$ In addition, the gene has been shown to affect the proliferation of megakaryocytes in mice. ${ }^{36}$ These findings strongly indicate the possible relevance for JMJD1C in relation to thrombocytopenia in our study. The variant rs10813766 in DOCK8 has previously been correlated to mean platelet volume in humans. ${ }^{32}$ The PPV reported in our material, $r s 10491684$, is in LD with $r s 10813766\left(r^{2}=0.05, D^{\prime}=1.00\right.$, GBR). Further, rs10491684 was also validated with the independent GWAS data. The last two genes in the pathway, CAPZA2 and KIF6, correlated to thrombocytopenia via the gene-based association analysis and the SNV association analysis, respectively. None of their associated variants were validated or had high CADD scores, however, because of the effects of the other genes within the same pathway, we still 
consider CAPZA2 and KIF6 to be potentially important. By combining the 17 SNVs represented by the four genes in the pathway "Factors involved in megakaryocyte development and platelet production", we could show that a wGRS model can predict which patients are at high or low toxicity risk levels, at least in this cohort. The 17 SNVs predictive validity was strengthened by showing how logistic regression models can predict CTCAE grade 3-4 and a large decrease in platelets with an AUC of $79 \%$ and $86 \%$, respectively. This gives sound credibility to the findings and adds to their potential clinical relevance. The results of "Hemostasis" and primarily "Factors involved in megakaryocyte development and platelet production" suggest that genetic variation within these pathways and genes, especially JMJD1C and DOCK8, might not only affect platelet status but could also have an important underlying effect on gemcitabine/carboplatin-induced thrombocytopenia.

The findings of this study have no overlaps with the previous extreme toxicity study that included 32 of these patients. ${ }^{10}$ There are probably multiple reasons for this; in the present study, we used the decrease and not the nadir, and we included more patients along with patients with intermediate toxicity (not only the extremes).

Initial association analyses showed that the investigated effects would be inadequate to demonstrate exome-wide statistical significance after correction for multiple testing using the Benjamini-Hochberg adjustment. This phenomenon is not limited to our study alone, it is the case for many studies of similar character. ${ }^{37}$ Therefore, we evaluated the nadir and decrease parameters using randomly shuffled permutations, which guided us to remove the nadir parameter completely as its effects seemed random. An analysis of the permutations showed that a P-value cut-off of 0.002 for the decrease toxicity parameters would yield the highest specificity in the analysis. One interesting side note is that the lowest $\mathrm{P}$-value is not necessarily the one with the greatest deviation from the random permutations; some false positives seem to have very low P-values. With that in mind, it is understandable why tophits in previous genome-wide studies have proven difficult to validate. We understand that the approach used in the present study will likely increase the number of false positives, however, the approach should also keep the true positives from the multi-factorial phenotypes within the reported results of the study. As a measure to reduce the number of false positives, we implemented the use of potentially pertinent variants and genes (PPVs and PPGs) where an SNV or gene association had to have a P-value $<0.002$ for two PVs (PV2 and PV4) to be considered to infer association. These results were then layered with validation and pathway enrichment to strengthen the credibility of the findings and circumvent the problem of false positives. This was done by anchoring the results to independently reported SNVs in LD with our PPVs and to relevant pathways for gemcitabine/carboplatin-induced thrombocytopenia. Another thing that should be kept in mind is that $D^{\prime}>0.33$ was used to indicate LD and, thus, add to the validity of the findings. This might not be optimal. However, $r^{2}$ does not give an accurate representation of $L D$ as we had low-frequency variants. $D^{\prime}$, on the other hand, is more robust and preferable when investigating low-frequency variants. ${ }^{38,39}$ However, both $r^{2}$ and $D^{\prime}$ are reported in the validation results, Table 2 .

The decrease toxicity parameter represents the magnitude of a change from baseline. From a doseresponse and a pharmacological perspective, this is what you would expect to have a correlation to genotype. Interestingly, the decrease parameter had a more pronounced optimum in the permutation tests than the nadir. From a clinical perspective, the nadir value might be of more interest, however, the decrease can easily be established by accounting for the baseline value.

\section{Concluding remarks}

We reported on variants and genes associated with the gemcitabine/carboplatin-induced ADR thrombocytopenia. When the results from the SNV and gene associations were layered with pathways 
and previously published findings, the results formed evidence for variants and genes possibly important for treatment-induced thrombocytopenia. The main pathways included "Hemostasis" and "Factors involved in megakaryocyte development and platelet production", which contain genes harboring the top SNVs found in the association analyses. We were able to validate some of these SNVs along with genes previously linked to platelet/thrombocyte function and formation. The SNVs in the latter pathway could be used to predict patients' risk/probability of severe thrombocytopenia (CTCAE 3-4) using both wGRSs and logistic regression models, something we hope can be validated in forthcoming studies. These results strongly support further investigation into using genetic markers as predictors for chemotherapy-induced thrombocytopenia; something that should not be limited to non-small cell lung cancer or gemcitabine/carboplatin chemotherapy but preferably also extended to other therapies where thrombocytopenia is an ADR.

\section{Acknowledgements}

This work was financially supported by grants from the Swedish Cancer Society (HG), the Swedish Research Council (HG), Linköping University (HG), ALF grants Region Östergötland (HG), the Funds of Radiumhemmet (RL and LDP), Marcus Borgströms stiftelse (HG), and the Spanish Ministry of Economy and Competitiveness [SAF2015-64850-R] (CR-A). The funders had no role in study design, data collection, data analysis, decision to publish, or preparation of the manuscript. We gratefully acknowledge the Science for Life Laboratory (SciLifeLab, Stockholm, Sweden), National Genomics Infrastructure (NGI, Sweden), NBIS (National Bioinformatics Infrastructure Sweden), and UPPMAX (Uppsala Multidisciplinary Center for Advanced Computational Science, Uppsala, Sweden) for providing massive parallel sequencing, computational infrastructure, and support.

\section{Conflict of interest}

The authors declare no conflicts of interest.

\section{Data availability statement}

The raw sequencing datasets generated and analyzed in this study are not publicly available because this is not permitted according to the ethical approval of the study. However, the datasets are available from the corresponding author upon reasonable request with the appropriate ethical approval.

\section{Supplementary Information}

Supplementary information is available at The Pharmacogenomics Journal's website. 


\section{References}

1. Torre LA, Bray F, Siegel RL, Ferlay J, Lortet-Tieulent J, Jemal A. Global cancer statistics, 2012. CA Cancer Journal for Clinicians 2015; 65(2): 87-108.

2. Siegel RL, Miller KD, Jemal A. Cancer statistics, 2015. CA Cancer Journal for Clinicians 2015; 65(1): 5-29.

3. Barton-Burke M. Gemcitabine: A pharmacologic and clinical overview. Cancer Nursing 1999; 22(2): 176-183.

4. Calvert AH, Harland SJ, Newell DR, Siddik ZH, Jones AC, McElwain TJ, et al. Early clinical studies with cis-diammine-1,1-cyclobutane dicarboxylate platinum II. Cancer Chemotherapy and Pharmacology 1982; 9(3): 140-147.

5. Gronberg BH, Bremnes RM, Flotten O, Amundsen T, Brunsvig PF, Hjelde HH, et al. Phase III study by the Norwegian lung cancer study group: pemetrexed plus carboplatin compared with gemcitabine plus carboplatin as first-line chemotherapy in advanced non-small-cell lung cancer. J Clin Oncol 2009; 27(19): 3217-3224.

6. Imamura F, Nishio M, Noro R, Tsuboi M, Ikeda N, Inoue A, et al. Randomized phase II study of two schedules of carboplatin and gemcitabine for stage IIIB and IV advanced non-small cell lung cancer (JACCRO LC-01 study). Chemotherapy 2011; 57(4): 357-362.

7. Rudd RM, Gower NH, Spiro SG, Eisen TG, Harper PG, Littler JAH, et al. Gemcitabine plus carboplatin versus mitomycin, ifosfamide, and cisplatin in patients with stage IIIB or IV nonsmall-cell lung cancer: A phase III randomized study of the London Lung Cancer Group. Journal of Clinical Oncology 2005; 23(1): 142-153.

8. Sederholm C, Hillerdal G, Lamberg K, Kolbeck K, Dufmats M, Westberg R, et al. Phase III trial of gemcitabine plus carboplatin versus single-agent gemcitabine in the treatment of locally advanced or metastatic non-small-cell lung cancer: the Swedish Lung Cancer Study Group. $J$ Clin Oncol 2005; 23(33): 8380-8388.

9. Zatloukal P, Petruželka L, Zemanová M, Kolek V, Skřičková J, Pešek M, et al. Gemcitabine plus cisplatin vs. gemcitabine plus carboplatin in stage IIIb and IV non-small cell lung cancer: A phase III randomized trial. Lung Cancer 2003; 41(3): 321-331.

10. Green H, Hasmats J, Kupershmidt I, Edsgard D, de Petris L, Lewensohn R, et al. Using WholeExome Sequencing to Identify Genetic Markers for Carboplatin and Gemcitabine-Induced Toxicities. Clin Cancer Res 2015.

11. Han B, Gao G, Wu W, Gao Z, Zhao X, Li L, et al. Association of ABCC2 polymorphisms with platinum-based chemotherapy response and severe toxicity in non-small cell lung cancer patients. Lung Cancer 2011; 72(2): 238-243.

12. Kiyotani K, Uno S, Mushiroda T, Takahashi A, Kubo M, Mitsuhata N, et al. A genome-wide association study identifies four genetic markers for hematological toxicities in cancer patients receiving gemcitabine therapy. Pharmacogenet Genomics 2012; 22(4): 229-235.

13. Qian J, Qu HQ, Yang L, Yin M, Wang Q, Gu S, et al. Association between CASP8 and CASP10 polymorphisms and toxicity outcomes with platinum-based chemotherapy in Chinese patients with non-small cell lung cancer. Oncologist 2012; 17(12): 1551-1561.

14. Low SK, Chung S, Takahashi A, Zembutsu H, Mushiroda T, Kubo M, et al. Genome-wide association study of chemotherapeutic agent-induced severe neutropenia/leucopenia for patients in Biobank Japan. Cancer Sci 2013; 104(8): 1074-1082.

15. Lamba JK, Fridley BL, Ghosh TM, Yu Q, Mehta G, Gupta P. Genetic variation in platinating agent and taxane pathway genes as predictors of outcome and toxicity in advanced non-small-cell lung cancer. Pharmacogenomics 2014; 15(12): 1565-1574. 
16. Cao S, Wang S, Ma H, Tang S, Sun C, Dai J, et al. Genome-wide association study of myelosuppression in non-small-cell lung cancer patients with platinum-based chemotherapy. The pharmacogenomics journal 2016; 16(1): 41-46.

17. Martin M. Cutadapt removes adapter sequences from high-throughput sequencing reads. EMBnetjournal 2011; 17(1): 10-12.

18. Langmead B, Salzberg SL. Fast gapped-read alignment with Bowtie 2. Nature Methods 2012; 9(4): 357-359.

19. Li H, Handsaker B, Wysoker A, Fennell T, Ruan J, Homer N, et al. The Sequence Alignment/Map format and SAMtools. Bioinformatics 2009; 25(16): 2078-2079.

20. Depristo MA, Banks E, Poplin R, Garimella KV, Maguire JR, Hartl C, et al. A framework for variation discovery and genotyping using next-generation DNA sequencing data. Nature Genetics 2011; 43(5): 491-501.

21. Danecek P, Auton A, Abecasis G, Albers CA, Banks E, DePristo MA, et al. The variant call format and VCFtools. Bioinformatics 2011; 27(15): 2156-2158.

22. Purcell S, Neale B, Todd-Brown K, Thomas L, Ferreira MAR, Bender D, et al. PLINK: A tool set for whole-genome association and population-based linkage analyses. American Journal of Human Genetics 2007; 81(3): 559-575.

23. RCoreTeam (2019). R: A language and environment for statistical computing. R Foundation for Statistical Computing, Vienna, Austria.

24. Kircher M, Witten DM, Jain P, O'Roak BJ, Cooper GM, Shendure J. A general framework for estimating the relative pathogenicity of human genetic variants. Nature Genetics 2014; 46(3): 310-315.

25. Ionita-Laza I, Lee S, Makarov V, Buxbaum JD, Lin X. Sequence kernel association tests for the combined effect of rare and common variants. American Journal of Human Genetics 2013; 92(6): 841-853.

26. Leandro-García LJ, Inglada-Pérez L, Pita G, Hjerpe E, Leskelä S, Jara C, et al. Genome-wide association study identifies ephrin type a receptors implicated in paclitaxel induced peripheral sensory neuropathy. Journal of Medical Genetics 2013; 50(9): 599-605.

27. Strachan T, Read AP. Human molecular genetics. 2011; 4 ed.: 482.

28. Kamburov A, Pentchev K, Galicka H, Wierling C, Lehrach H, Herwig R. ConsensusPathDB: Toward a more complete picture of cell biology. Nucleic Acids Research 2011; 39(SUPPL. 1): D712-D717.

29. Sing T, Sander O, Beerenwinkel N, Lengauer T. ROCR: visualizing classifier performance in R. Bioinformatics 2005; 21(20): 3940-3941.

30. Ding $Q$, Wang $M, X u G, Y e X, X i X, Y u T$, et al. Molecular basis and thrombotic manifestations of antithrombin deficiency in 15 unrelated Chinese patients. Thromb Res 2013; 132(3): 367-373.

31. van Boven HH, Vandenbroucke JP, Briet E, Rosendaal FR. Gene-gene and gene-environment interactions determine risk of thrombosis in families with inherited antithrombin deficiency. Blood 1999; 94(8): 2590-2594.

32. Gieger C, Radhakrishnan A, Cvejic A, Tang W, Porcu E, Pistis G, et al. New gene functions in megakaryopoiesis and platelet formation. Nature 2011; 480(7376): 201-208.

33. Eicher JD, Xue L, Ben-Shlomo Y, Beswick AD, Johnson AD. Replication and hematological characterization of human platelet reactivity genetic associations in men from the Caerphilly Prospective Study (CaPS). J Thromb Thrombolysis 2016; 41(2): 343-350.

34. Shameer K, Denny JC, Ding K, Jouni H, Crosslin DR, de Andrade M, et al. A genome- and phenome-wide association study to identify genetic variants influencing platelet count and volume and their pleiotropic effects. Hum Genet 2014; 133(1): 95-109. 
35. Soranzo N, Spector TD, Mangino M, Kuhnel B, Rendon A, Teumer A, et al. A genome-wide metaanalysis identifies 22 loci associated with eight hematological parameters in the HaemGen consortium. Nat Genet 2009; 41(11): 1182-1190.

36. Kitajima K, Kojima M, Kondo S, Takeuchi T. A role of jumonji gene in proliferation but not differentiation of megakaryocyte lineage cells. Exp Hematol 2001; 29(4): 507-514.

37. Sham PC, Purcell SM. Statistical power and significance testing in large-scale genetic studies. Nat Rev Genet 2014; 15(5): 335-346.

38. Lin CY, Xing G, Ku HC, Elston RC, Xing C. Enhancing the power to detect low-frequency variants in genome-wide screens. Genetics 2014; 196(4): 1293-1302.

39. Slatkin M. Linkage disequilibrium--understanding the evolutionary past and mapping the medical future. Nat Rev Genet 2008; 9(6): 477-485. 


\section{Figures and figure legends}

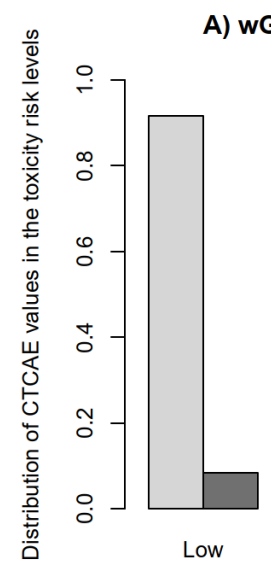

A) wGRS for thrombocytopenia CTCAE

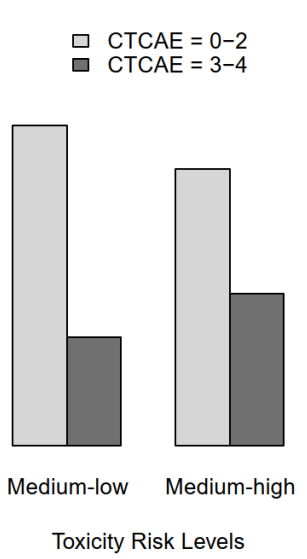

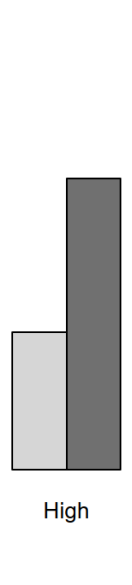

B) wGRS for thrombocytopenia decrease

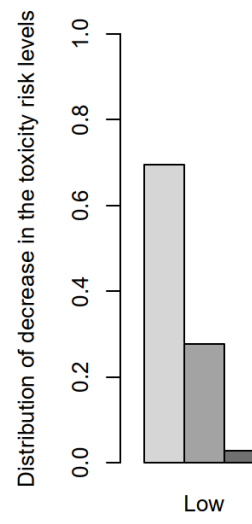

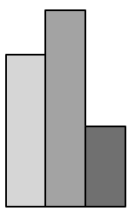

Medium-high

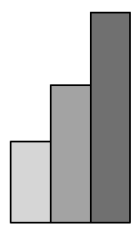

High

Figure 1. Weighted genetic risk score (wGRS) for thrombocytopenia.

A) Shows the distributions of Common Terminology Criteria for Adverse Events (CTCAE) grades grouped as grades 0-2 and 3-4 at the different toxicity risk levels (low, medium-low, medium-high, and high) that patients were predicted to using wGRS. B) Shows the distributions of the platelet decrease (small, medium, or large) at the different toxicity risk levels (low, medium-low, medium-high, and high) that patients were predicted to using wGRS. 


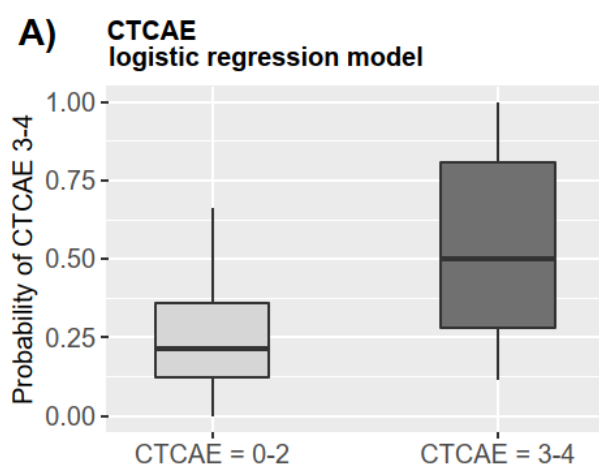

\section{B) CTCAE}

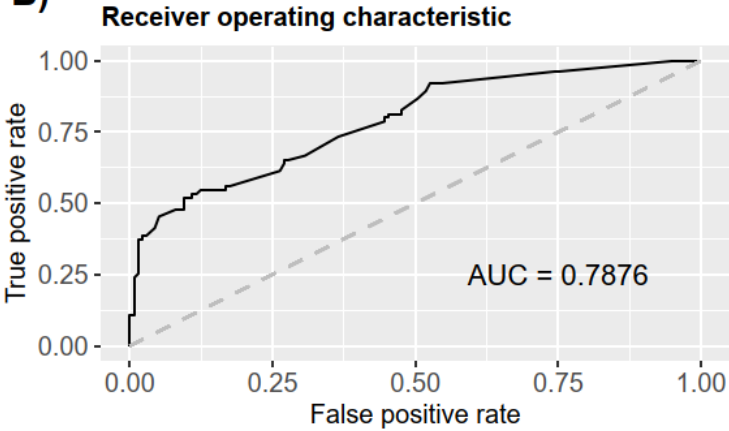

D) Decrease

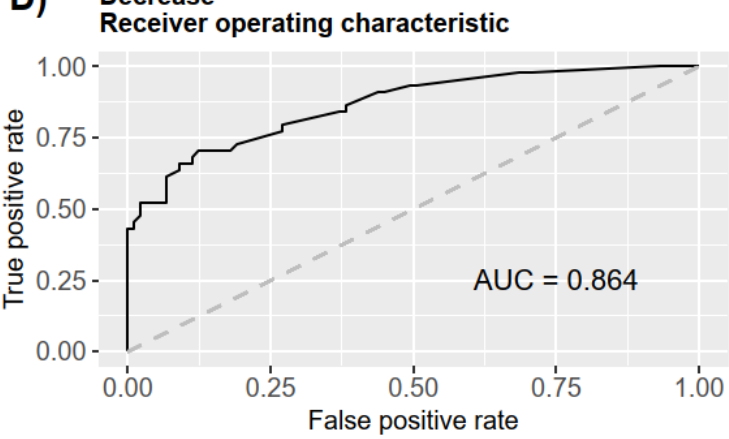

Figure 2. Logistic regression models for thrombocytopenia.

A) Predicted probability of thrombocytopenia CTCAE grades 3-4 for the patients separated on registered CTCAE grades. B) Receiver operator characteristics (ROC) curve of the thrombocytopenia CTCAE model predictions. C) Predicted probability of a large decrease of platelets ( $\leq 10 \%$ of the baseline value) for the patients separated on if they experienced a small ( $>25 \%$ ) or a large decrease. D) ROC curve of the platelet decrease model predictions. 


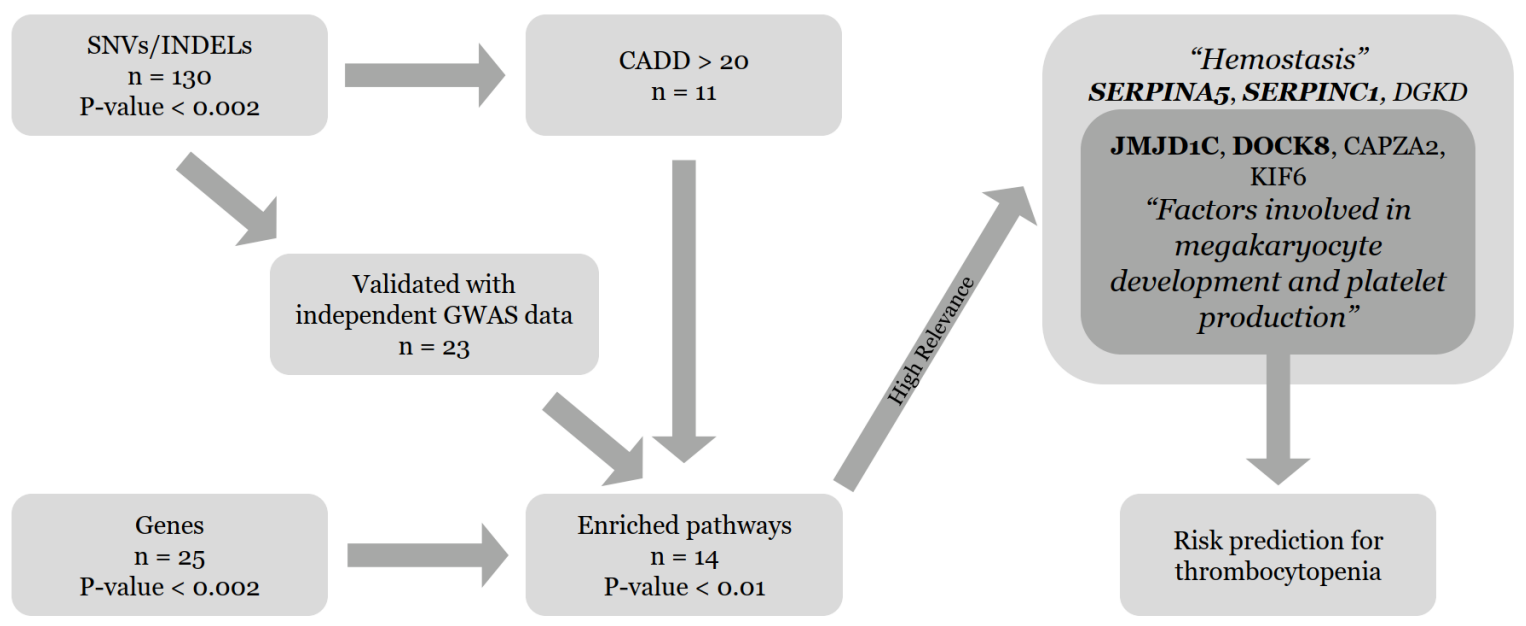

Figure 3. Overview of the statistical methods and their output.

The associations found 130 SNVs (PPVs) and 25 genes (PPGs). The variants were scored using CADD (Combined Annotation-Dependent Depletion), and 23 variants were validated using independent data. Using all unique genes $(n=45)$ represented by PPGs, validated PPVs, or PPVs with a CADD score $>20$, we found 14 enriched pathways. The two top pathways are of primary interest and showed high relevance to the investigated phenotype, thrombocytopenia. The genes in bold include SNVs with high CADD scores or validated variants. Lastly, the SNVs included in the most relevant pathway were used to construct weighted genetic risk scores (wGRS) and logistic regression models for predicting the risk of thrombocytopenia. 


\section{Tables and table legends}

Table 1. Patient Characteristics.

Baseline characteristics of patients and thrombocytopenia during the first cycle graded according to the National Cancer Institute's Common Terminology Criteria for Adverse Events (CTCAE) version 4.03.

Gender, N (\%)

\begin{tabular}{rrr} 
Male & 100 & $(47.2 \%)$ \\
Female & 112 & $(52.8 \%)$ \\
\hline
\end{tabular}

Age, in years, median (range)

\begin{tabular}{rrr} 
All & 64 & $(45-82)$ \\
Male & 66.5 & $(45-82)$ \\
Female & 63.5 & $(47-80)$ \\
\hline
\end{tabular}

Clinical stage, $\mathbf{N}(\%)$

\begin{tabular}{rrr} 
Stage I & 40 & $(18.9 \%)$ \\
Stage II & 28 & $(13.2 \%)$ \\
Stage III & 63 & $(29.7 \%)$ \\
Stage IV & 79 & $(37.3 \%)$ \\
not specified & 2 & $(0.9 \%)$ \\
\hline
\end{tabular}

Histological classifications, N (\%)

\begin{tabular}{rrr} 
Adenocarcinoma (AC) & 132 & $(62.3 \%)$ \\
Squamous cell carcinomas (SCC) & 40 & $(18.9 \%)$ \\
Non-small cell lung cancer (NSCLC) & 29 & $(13.7 \%)$ \\
Large cell carcinoma (LLC) & 10 & $(4.7 \%)$ \\
Other & 1 & $(0.5 \%)$ \\
\hline
\end{tabular}

Smoking history, N (\%)

\begin{tabular}{ccc} 
Current & 92 & $(43.4 \%)$ \\
Former & 99 & $(46.7 \%)$ \\
Never & 21 & $(9.9 \%)$ \\
\hline
\end{tabular}

Thrombocytopenia, CTCAE grade, $\mathbf{N}(\%)$

\begin{tabular}{rrr}
0 & 43 & $(20.3 \%)$ \\
1 & 50 & $(23.6 \%)$ \\
2 & 44 & $(20.8 \%)$ \\
3 & 44 & $(20.8 \%)$ \\
4 & 31 & $(14.6 \%)$ \\
5 & 0 & $(0.0 \%)$ \\
\hline
\end{tabular}


1 Table 2. Validated PPVs for thrombocytopenia.

2 Validated PPVs for thrombocytopenia and their respective validation SNV(s) along with $r^{2}$ and D' values. A D'>0.33 was considered to indicate linkage

3 disequilibrium.

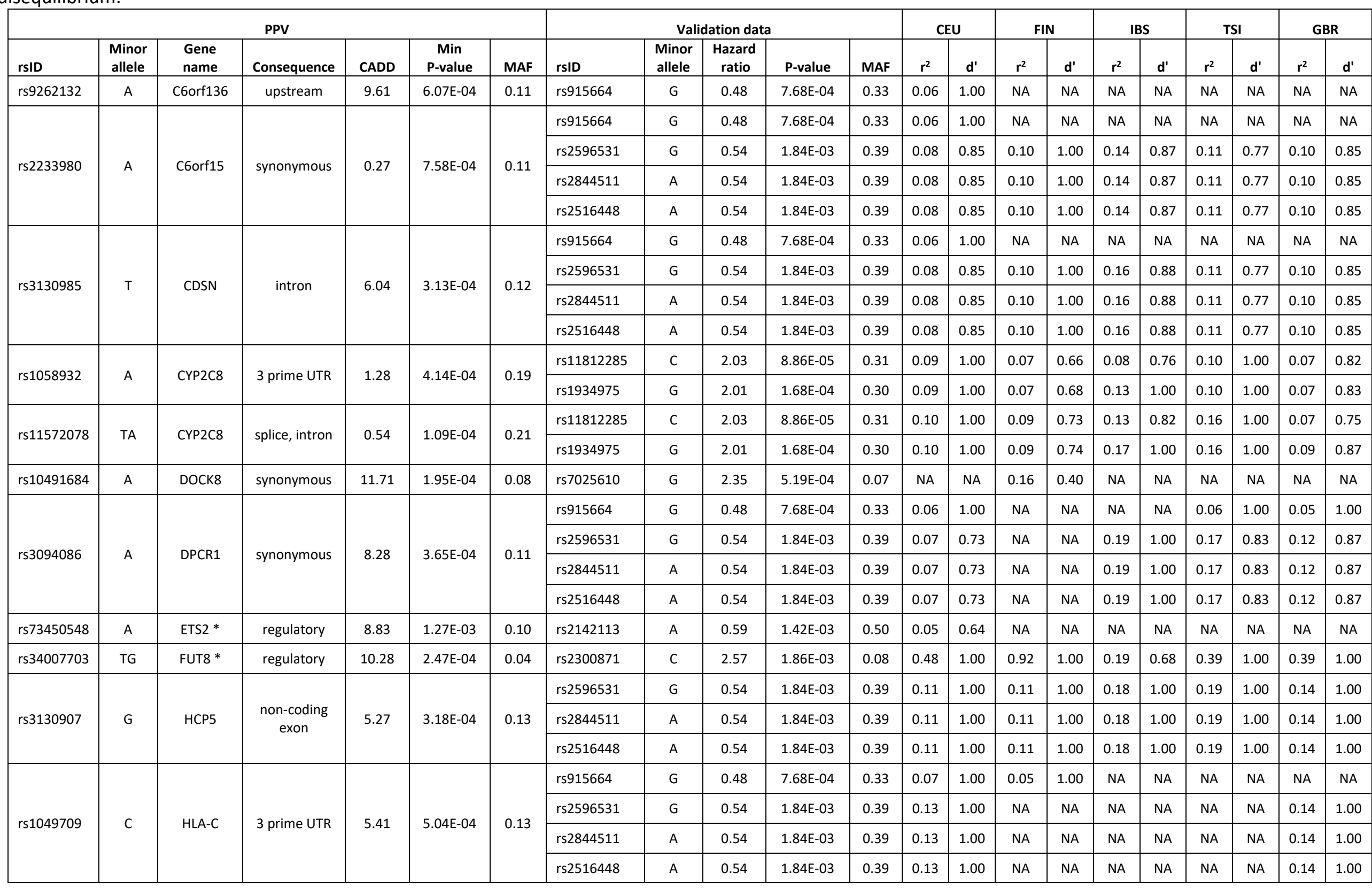




\begin{tabular}{|c|c|c|c|c|c|c|c|c|c|c|c|c|c|c|c|c|c|c|c|c|c|}
\hline rs886424 & $\mathrm{T}$ & LINC00243 & $\begin{array}{c}\text { non-coding } \\
\text { exon }\end{array}$ & 4.70 & $2.74 \mathrm{E}-04$ & 0.10 & rs915664 & G & 0.48 & 7.68E-04 & 0.33 & 0.07 & 1.00 & NA & NA & NA & NA & NA & NA & NA & NA \\
\hline rs886423 & $\mathrm{C}$ & LINC00243 & $\begin{array}{c}\text { non-coding } \\
\text { exon }\end{array}$ & 2.52 & 7.87E-04 & 0.14 & rs915664 & G & 0.48 & $7.68 \mathrm{E}-04$ & 0.33 & 0.08 & 1.00 & 0.05 & 1.00 & 0.11 & 1.00 & 0.05 & 1.00 & 0.05 & 1.00 \\
\hline \multirow{3}{*}{ rs3115672 } & \multirow{3}{*}{$\mathrm{T}$} & \multirow{3}{*}{ MSH5 } & \multirow{3}{*}{ synonymous } & \multirow{3}{*}{11.39} & \multirow{3}{*}{$3.43 \mathrm{E}-04$} & \multirow{3}{*}{0.13} & rs2596531 & $\mathrm{G}$ & 0.54 & $1.84 \mathrm{E}-03$ & 0.39 & 0.08 & 1.00 & 0.11 & 1.00 & 0.08 & 0.70 & 0.09 & 0.75 & 0.12 & 1.00 \\
\hline & & & & & & & rs2844511 & A & 0.54 & $1.84 \mathrm{E}-03$ & 0.39 & 0.08 & 1.00 & 0.11 & 1.00 & 0.08 & 0.70 & 0.09 & 0.75 & 0.12 & 1.00 \\
\hline & & & & & & & rs2516448 & A & 0.54 & $1.84 \mathrm{E}-03$ & 0.39 & 0.08 & 1.00 & 0.11 & 1.00 & 0.08 & 0.70 & 0.09 & 0.75 & 0.12 & 1.00 \\
\hline rs9262143 & $\mathrm{T}$ & PPP1R18 & missense & 32.00 & $1.34 \mathrm{E}-04$ & 0.11 & rs915664 & G & 0.48 & $7.68 \mathrm{E}-04$ & 0.33 & 0.06 & 1.00 & NA & NA & NA & NA & NA & NA & NA & NA \\
\hline \multirow{3}{*}{ rs10885 } & \multirow{3}{*}{$\mathrm{T}$} & \multirow{3}{*}{ PRRC2A } & \multirow{3}{*}{ missense } & \multirow{3}{*}{24.20} & \multirow{3}{*}{$8.61 \mathrm{E}-04$} & \multirow{3}{*}{0.20} & rs2596531 & G & 0.54 & $1.84 \mathrm{E}-03$ & 0.39 & 0.12 & 1.00 & 0.22 & 0.92 & NA & NA & 0.06 & 0.35 & 0.15 & 0.81 \\
\hline & & & & & & & rs2844511 & A & 0.54 & $1.84 \mathrm{E}-03$ & 0.39 & 0.12 & 1.00 & 0.22 & 0.92 & NA & NA & 0.06 & 0.35 & 0.15 & 0.81 \\
\hline & & & & & & & rs 2516448 & A & 0.54 & $1.84 \mathrm{E}-03$ & 0.39 & 0.12 & 1.00 & 0.22 & 0.92 & NA & NA & 0.06 & 0.35 & 0.15 & 0.81 \\
\hline \multirow{3}{*}{ rs11229 } & \multirow{3}{*}{ G } & \multirow{3}{*}{ PRRC2A } & \multirow{3}{*}{ synonymous } & \multirow{3}{*}{5.59} & \multirow{3}{*}{$8.61 \mathrm{E}-04$} & \multirow{3}{*}{0.20} & rs2596531 & $\mathrm{G}$ & 0.54 & $1.84 \mathrm{E}-03$ & 0.39 & 0.12 & 1.00 & 0.22 & 0.92 & NA & NA & 0.06 & 0.35 & 0.15 & 0.81 \\
\hline & & & & & & & rs2844511 & A & 0.54 & $1.84 \mathrm{E}-03$ & 0.39 & 0.12 & 1.00 & 0.22 & 0.92 & NA & NA & 0.06 & 0.35 & 0.15 & 0.81 \\
\hline & & & & & & & rs2516448 & A & 0.54 & $1.84 \mathrm{E}-03$ & 0.39 & 0.12 & 1.00 & 0.22 & 0.92 & NA & NA & 0.06 & 0.35 & 0.15 & 0.81 \\
\hline rs6113 & C & SERPINA5 & synonymous & 0.01 & $1.63 \mathrm{E}-03$ & 0.11 & rs3790036 & G & 1.91 & $1.47 \mathrm{E}-03$ & 0.16 & 0.07 & 0.33 & NA & NA & NA & NA & NA & NA & NA & NA \\
\hline rs6119 & G & SERPINA5 & missense & 0.00 & $6.13 \mathrm{E}-04$ & 0.10 & rs3790036 & G & 1.91 & $1.47 \mathrm{E}-03$ & 0.16 & 0.07 & 0.33 & NA & NA & NA & NA & NA & NA & NA & NA \\
\hline \multirow{2}{*}{ rs5877 } & \multirow{2}{*}{$\mathrm{C}$} & \multirow{2}{*}{ SERPINC1 } & \multirow{2}{*}{ synonymous } & \multirow{2}{*}{0.10} & \multirow{2}{*}{$1.07 \mathrm{E}-03$} & \multirow{2}{*}{0.33} & rs 12079820 & G & 2.07 & $9.42 \mathrm{E}-04$ & 0.40 & 0.41 & 0.64 & NA & NA & 0.28 & 0.54 & 0.34 & 0.59 & 0.49 & 0.84 \\
\hline & & & & & & & rs10912773 & A & 2.07 & $9.42 \mathrm{E}-04$ & 0.40 & 0.41 & 0.64 & NA & NA & 0.28 & 0.54 & 0.34 & 0.59 & 0.49 & 0.84 \\
\hline & & & & & & & rs2596531 & G & 0.54 & $1.84 \mathrm{E}-03$ & 0.39 & 0.13 & 0.82 & 0.10 & 0.71 & 0.09 & 0.47 & 0.14 & 0.74 & 0.10 & 0.75 \\
\hline rs1800629 & A & TNF * & regulatory & 1.54 & $2.92 \mathrm{E}-04$ & 0.19 & rs2844511 & A & 0.54 & $1.84 \mathrm{E}-03$ & 0.39 & 0.13 & 0.82 & 0.10 & 0.71 & 0.09 & 0.47 & 0.14 & 0.74 & 0.10 & 0.75 \\
\hline & & & & & & & rs2516448 & A & 0.54 & $1.84 \mathrm{E}-03$ & 0.39 & 0.13 & 0.82 & 0.10 & 0.71 & 0.09 & 0.47 & 0.14 & 0.74 & 0.10 & 0.75 \\
\hline rs6504649 & G & XYLT2 & missense & 6.18 & $1.52 \mathrm{E}-03$ & 0.37 & rs2103273 & $A$ & 2.38 & $1.51 \mathrm{E}-04$ & 0.18 & NA & NA & 0.06 & 0.55 & NA & NA & NA & NA & NA & NA \\
\hline
\end{tabular}

4 Note: PPV rsIDs in the first column are sorted according to Gene Name, CADD score and validation SNP P-value. Variants validated by multiple SNVs are within

5 the same horizontal boxes marked with lines. Variants within the same genes are marked with thick border lines. * gene closest to the variant.

6 Abbreviations: NA, not available; PPV, potentially pertinent variant; CADD, Combined Annotation-Dependent Depletion; SNV, single nucleotide variant; PV,

7 phenotype value; Min P-value, the minimal P-value from the SNV association analysis; MAF, minor allele frequency; CEU, Utah residents with Northern and

8 Western European ancestry; FIN, Finnish in Finland; GBR, British in England and Scotland; IBS, Iberian populations in Spain; TSI, Toscani in Italia; UTR,

9 untranslated region. 
10 Table 3. Enriched Pathways.

11 All enriched pathways with a P-value $<0.01$ and a minimum two-gene overlap using all unique genes $(n=45)$ represented by PPGs, validated

12 PPVs, or PPVs with a CADD > 20.

\begin{tabular}{|c|c|c|c|c|c|}
\hline Pathway name & Genes matched to the pathway & Pathway size & P-value & Pathway source & Pathway identification in source \\
\hline $\begin{array}{l}\text { Factors involved in megakaryocyte } \\
\text { development and platelet production }\end{array}$ & KIF6; CAPZA2; DOCK8; JMJD1C & 131 & $3.34 \mathrm{E}-04$ & Reactome & R-HSA-983231 \\
\hline Hemostasis & $\begin{array}{l}\text { CAPZA2; DOCK8; SERPINA5; } \\
\text { SERPINC1; KIF6; JMJD1C; DGKD }\end{array}$ & 668 & $1.27 \mathrm{E}-03$ & Reactome & R-HSA-109582 \\
\hline Intrinsic Pathway of Fibrin Clot Formation & SERPINA5; SERPINC1 & 22 & $1.43 \mathrm{E}-03$ & Reactome & R-HSA-140837 \\
\hline Common Pathway of Fibrin Clot Formation & SERPINA5; SERPINC1 & 22 & $1.43 \mathrm{E}-03$ & Reactome & R-HSA-140875 \\
\hline Membrane Trafficking & $\begin{array}{l}\text { CAPZA2; KIF6; CHM; CLTCL1; } \\
\text { SPTBN5; BIN1 }\end{array}$ & 582 & $3.25 \mathrm{E}-03$ & Reactome & R-HSA-199991 \\
\hline Endocytosis - Homo sapiens (human) & HLA-C; CLTCL1; BIN1; CAPZA2 & 244 & 3.35E-03 & KEGG & path:hsa04144 \\
\hline Allograft rejection - Homo sapiens (human) & HLA-C; TNF & 38 & $4.01 \mathrm{E}-03$ & KEGG & path:hsa05330 \\
\hline Vesicle-mediated transport & $\begin{array}{l}\text { CAPZA2; KIF6; CHM; CLTCL1; } \\
\text { SPTBN5; BIN1 }\end{array}$ & 620 & $4.43 \mathrm{E}-03$ & Reactome & R-HSA-5653656 \\
\hline Formation of Fibrin Clot (Clotting Cascade) & SERPINA5; SERPINC1 & 39 & 4.45E-03 & Reactome & R-HSA-140877 \\
\hline $\begin{array}{l}\text { Graft-versus-host disease - Homo sapiens } \\
\text { (human) }\end{array}$ & HLA-C; TNF & 41 & $4.91 \mathrm{E}-03$ & KEGG & path:hsa05332 \\
\hline $\begin{array}{l}\text { Type I diabetes mellitus - Homo sapiens } \\
\text { (human) }\end{array}$ & HLA-C; TNF & 43 & $5.39 \mathrm{E}-03$ & KEGG & path:hsa04940 \\
\hline keratinocyte differentiation & ETS2; TNF & 53 & 8.09E-03 & BioCarta & keratinocytepathway \\
\hline $\begin{array}{l}\text { Transport to the Golgi and subsequent } \\
\text { modification }\end{array}$ & CAPZA2; SPTBN5; FUT8 & 168 & 8.94E-03 & Reactome & R-HSA-948021 \\
\hline Complement and Coagulation Cascades & SERPINA5; SERPINC1 & 59 & $9.95 \mathrm{E}-03$ & Wikipathways & WP558 \\
\hline
\end{tabular}

13 Abbreviations: PPV, potentially pertinent variant; PPG, potentially pertinent gene; CADD, Combined Annotation-Dependent Depletion. 
14 Table 4. Statistics of the wGRS.

15 Comparison of the distribution of CTCAE and decrease in the wGRS toxicity risk levels using Fisher's exact test in R.

\begin{tabular}{|c|c|c|c|c|c|c|c|c|c|c|c|c|c|c|c|}
\hline \multicolumn{2}{|c|}{ wGRS } & \multicolumn{5}{|c|}{ CTCAE } & \multicolumn{3}{|c|}{ Decrease } & \multicolumn{3}{|c|}{ CTCAE $0-2$ vs. $3-4$} & \multicolumn{3}{|c|}{ Small vs. Large Decrease } \\
\hline Toxicity risk level & Risk score & 0 & 1 & 2 & 3 & 4 & Small & Medium & Large & OR & $95 \% \mathrm{Cl}$ & P-value & OR & $95 \% \mathrm{Cl}$ & P-value \\
\hline Low & $>-0.2225$ & 16 & 7 & 10 & 2 & 1 & 25 & 10 & 1 & REF & - & - & REF & - & - \\
\hline Medium low & $-0.5267--0.2225$ & 15 & 26 & 15 & 12 & 7 & 37 & 30 & 8 & 3.69 & $0.98-20.96$ & $4.25 \mathrm{E}-02$ & 5.31 & $0.64-248.98$ & $1.41 \mathrm{E}-01$ \\
\hline Medium high & $-0.8667--0.5267$ & 8 & 10 & 13 & 10 & 7 & 17 & 22 & 9 & 5.91 & $1.50-34.54$ & $4.33 \mathrm{E}-03$ & 12.66 & $1.52-600.73$ & $1.09 \mathrm{E}-02$ \\
\hline \multirow[t]{2}{*}{ High } & $<-0.8667$ & 4 & 7 & 6 & 20 & 16 & 10 & 17 & 26 & 22.35 & $5.82-129.50$ & $1.55 \mathrm{E}-08$ & 66.82 & $8.83-3015.75$ & $5.92 \mathrm{E}-09$ \\
\hline & Total: & 43 & 50 & 44 & 44 & 31 & 89 & 79 & 44 & & & & & & \\
\hline
\end{tabular}

16 Abbreviations: wGRS, weighted genetic risk scores; CTCAE, common terminology criteria for adverse events; OR, odds ratio; $\mathrm{Cl}$, confidence 17 interval; REF, reference. 
A

Identity by descent (IBD)

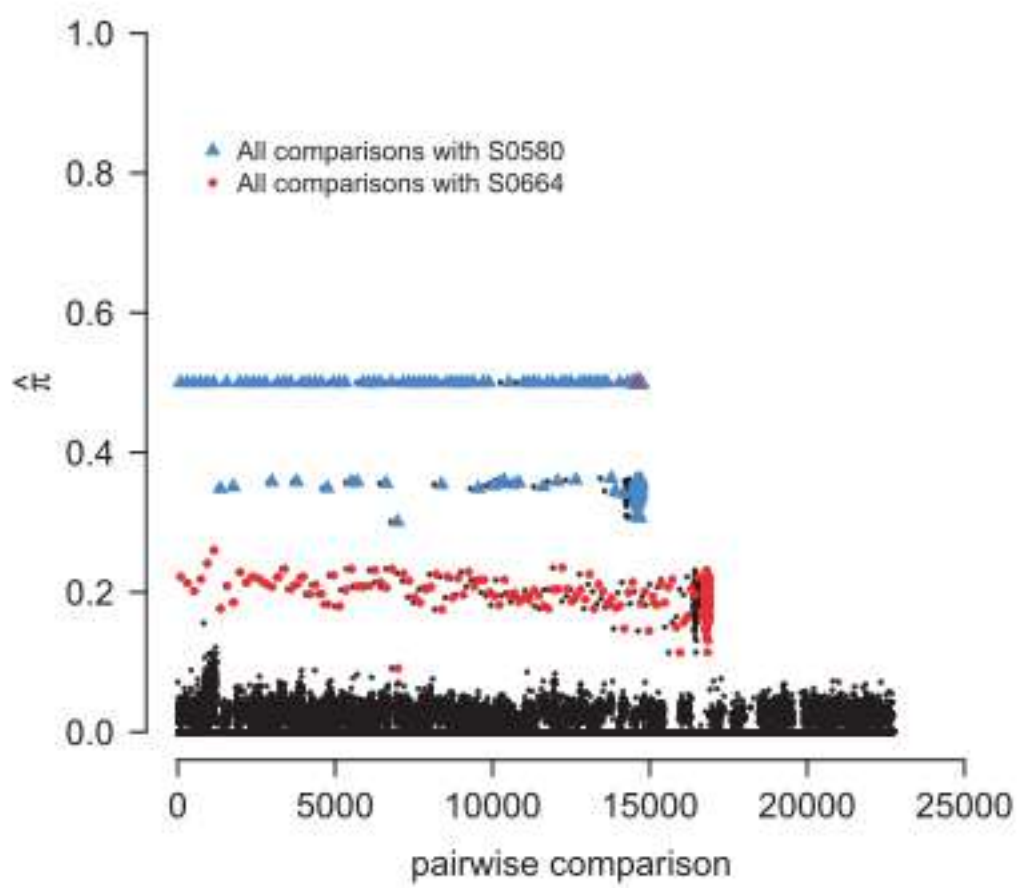

B
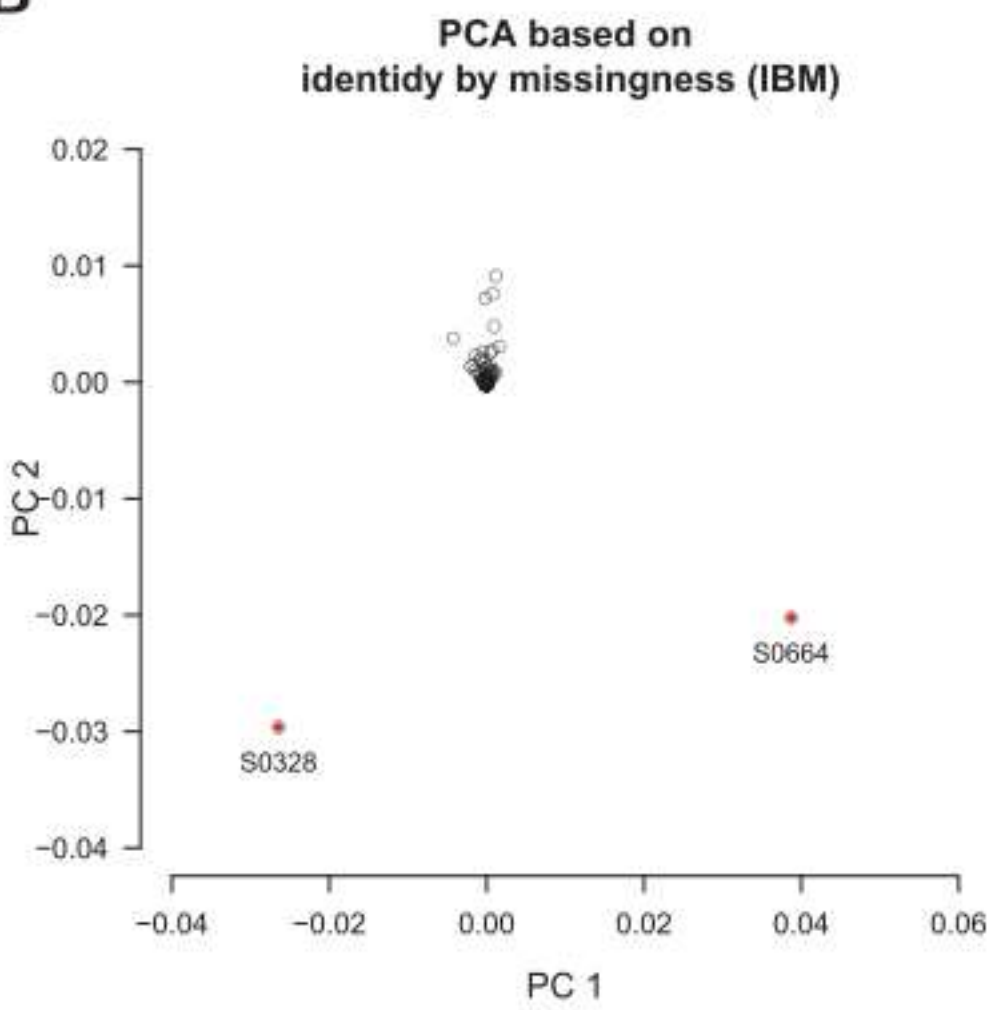

Supplementary Figure S1. Identification of sample outliers by identity by descent and (IBD) and identity by missingness (IBM).

As mentioned in Materials and Methods, three samples out of the original 215 were removed from the analysis. After all filtering steps the program PLINK was used to identify outliers; first through identity by descent (IBD) and then through identity by missingness (IBM). IBD identifies how many of the variants are shared between the samples (A). There it is apparent that samples 50580 and $S 0664$ share variants with other samples at a much higher rate than the rest of the cohort. While the exact reasons for this remain unknown, one possible explanation is that these samples were contaminated and/or mixed in some way prior to sequencing. In any case, to not include them in the association analysis, was regarded as the safe approach. IBM clusters the samples based on missing genotypes (B). There it is shown that samples S0328 and S0664 deviate from the other samples. Sample 50328 was, therefore, also regarded as unreliable and removed from the analysis.

Thus, 212 of the original 215 samples were used in the subsequent association analysis. 


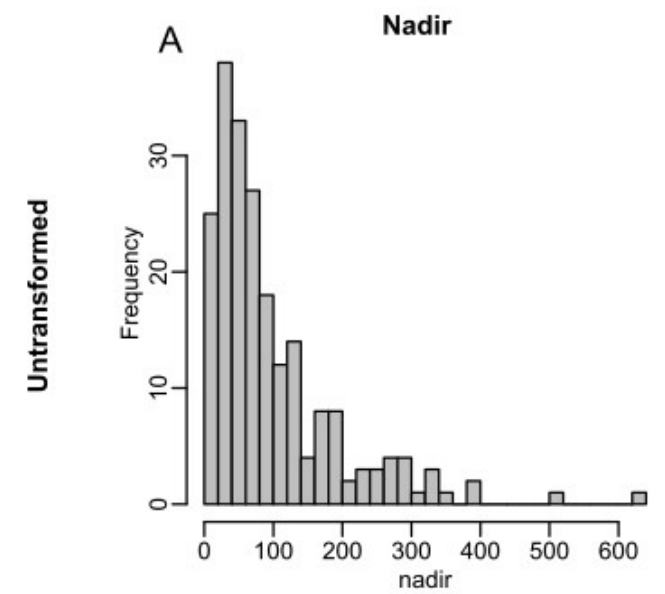

C

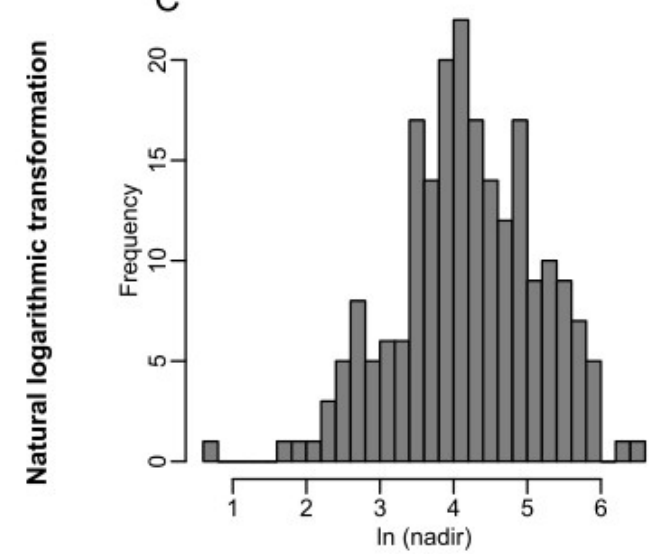

$E$

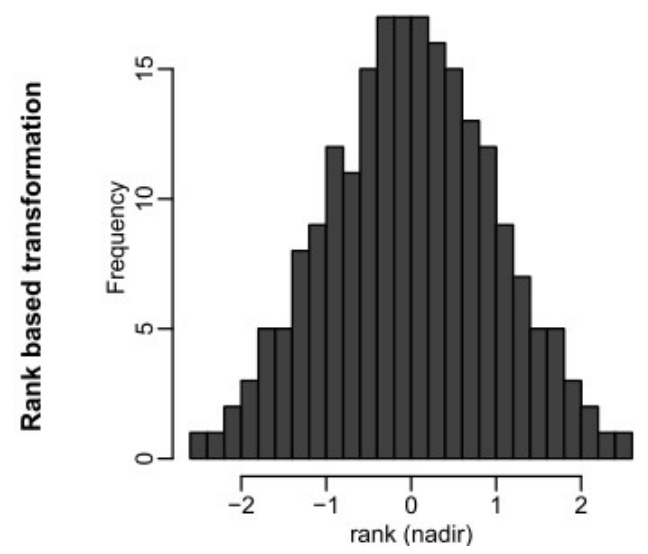

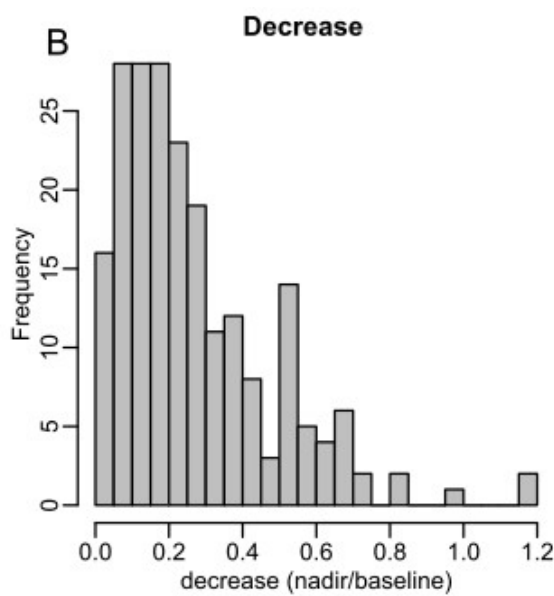

$\mathrm{D}$

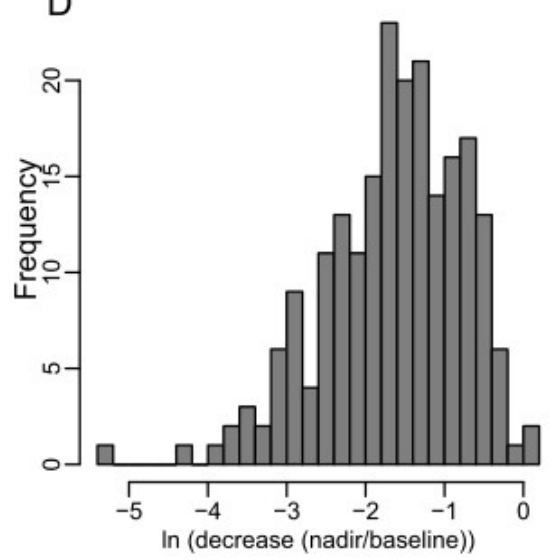

$\mathrm{F}$

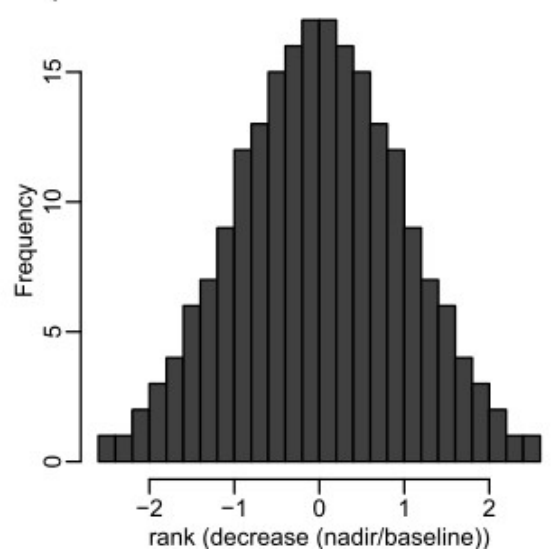

Supplementary Figure S2. Visualization of normalization of nadir and decrease using natural logarithmic and rank-based (tRank) transformation.

The top row shows the right-skewed distribution of the unnormalized distribution of nadir (A) and decrease (B).

The middle row shows the nadir $(C)$ and the decrease $(D)$ after normalization using the natural logarithmic transformation in $R$. The bottom row shows the nadir (E) and the decrease (F) after normalization using the rank-based transformation tRank in the $R$-package multic. Both transformations give the distributions a more Gaussian curve compared to the distribution of the untransformed data. The logarithmic distributions shown in the middle row is what is referred to in the main text as phenotype value 1 (PV1) and phenotype value 2 (PV2) for nadir and decrease, respectively. The rank-based distribution in the bottom row is what is referred to in the main text as phenotype value 3 (PV3) and phenotype value 4 (PV4) for nadir and decrease, respectively. 


\section{Supplementary Figure S3}

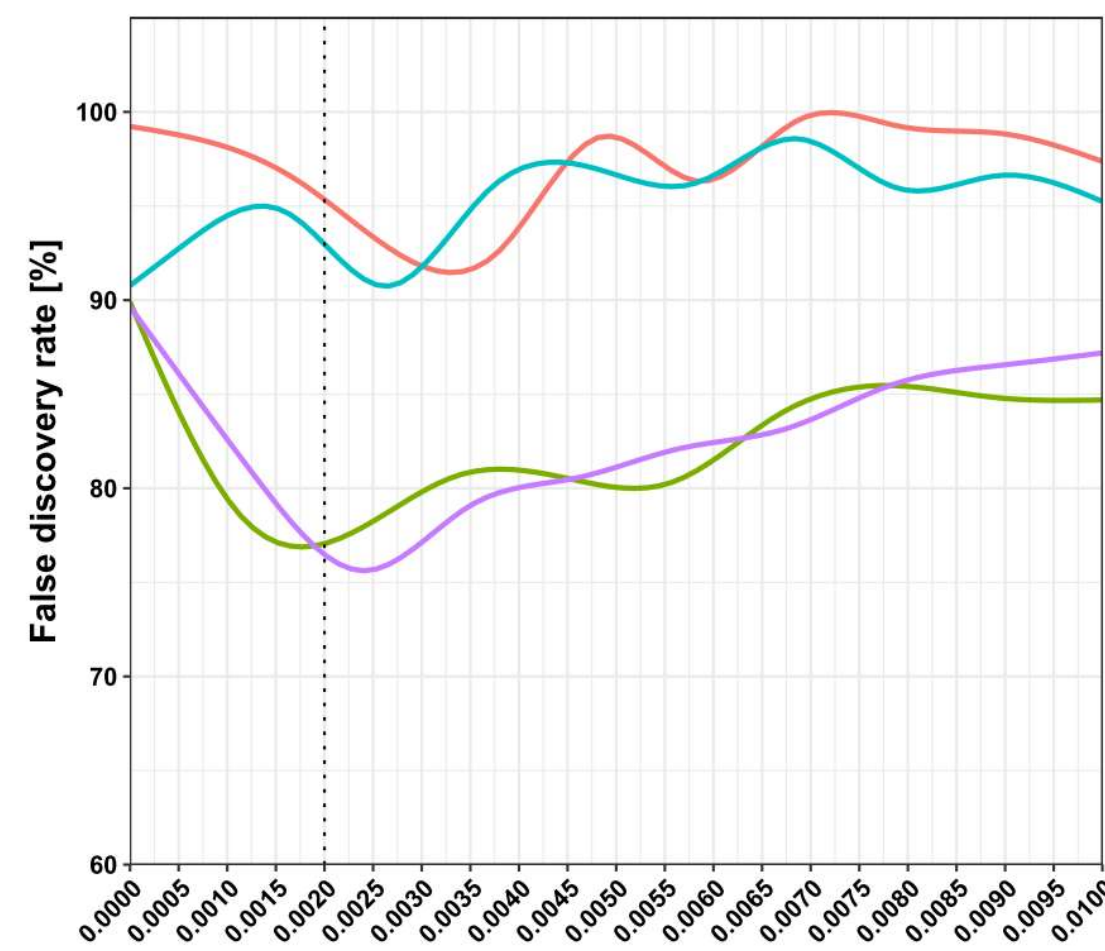

P-value cut-off

\section{Phenotype value}

- PV1: natural logarithm transformation of nadir values

_ PV2: natural logarithm transformation of the decrease

- PV3: rank-based transformation of nadir values

PV4: rank-based transformation of the decrease

Supplementary Figure S3. Visualization of permutations for PV1-PV4 and choice of P-value cut-off.

Results from the permutations ( $n=1000)$ using randomly shuffled values for PV1-PV4 comparing the false discovery rate (FDR) between the permutations and the test with the true phenotype values (all done using the SNV association analysis setup adjusted for age and gender in PLINK) at different P-value cut-offs ranging from $0.01-0.00001$. For the nadir values in PV1 and PV3, we see that the FDR is between 90-100\%, even for low P-values. Therefore, PV1 and PV3 were discarded from the remaining statistical analyses as the results from them would be deemed highly unreliable. For the decrease parameter in PV2 and PV4, however, we see the FDR going down with a lower P-value cut-off until a point where the FDRs goes up sharply again. From this, the P-value cut-off 0.002 (represented by the dotted line) was chosen to be used in the study. This cut-off shows the lowest FDR (roughly $77 \%$ ) for PV2 and PV4 combined. The cut-off will include many false positives and at the same time still, include the true positives. Lowering the cut-off more will increase the number of false positives and decrease the number of true positives. An interesting note here is that the lowest $P$-values tend to be among the worst, meaning that they are likely to reflect a random effect in the data. This is somewhat alarming considering that studies are, naturally, focused on the variants with the lowest $P$-values in their dataset. 


\section{Genes and variants in hematopoiesis-related pathways are associated with gemcitabine/carboplatin-induced thrombocytopenia}

Niclas Björn ${ }^{1}$, Benjamín Sigurgeirsson ${ }^{2,3}$, Anna Svedberg ${ }^{1}$, Sailendra Pradhananga ${ }^{2}$, Eva Brandén ${ }^{4,5}$, Hirsh Koyi $^{4,5}$, Rolf Lewensohn ${ }^{6}$, Luigi De Petris ${ }^{6}$, Maria Apellániz-Ruiz ${ }^{7}$, Cristina Rodríguez-Antona ${ }^{7}$, Joakim Lundeberg ${ }^{2, \&}$ and Henrik Gréen ${ }^{1,2,8, \&, *}$

${ }^{1}$ Clinical Pharmacology, Division of Drug Research, Department of Medical and Health Sciences, Linköping University, Linköping, Sweden

${ }^{2}$ Science for Life Laboratory, School of Engineering Sciences in Chemistry, Biotechnology and Health, Division of Gene Technology, KTH Royal Institute of Technology, Solna, Sweden

${ }^{3}$ School of Engineering and Natural Sciences, University of Iceland, Reykjavík, Iceland

${ }^{4}$ Department of Respiratory Medicine, Gävle Hospital, Gävle, Sweden

${ }^{5}$ Centre for Research and Development, Uppsala University/Region Gävleborg, Gävle, Sweden

${ }^{6}$ Thoracic Oncology Unit, Tema Cancer, Karolinska University Hospital, and Department of OncologyPathology, Karolinska Institutet, Stockholm, Sweden

${ }^{7}$ Hereditary Endocrine Cancer Group, Spanish National Cancer Research Centre (CNIO), Madrid, Spain

${ }^{8}$ Department of Forensic Genetics and Forensic Toxicology, National Board of Forensic Medicine, Linköping, Sweden

\& JL and HG share the last authorship.

* Corresponding author E-mail: henrik.green@liu.se

\section{Supplementary Material S1}

\section{Independent GWAS data used for validation}

Germline DNA samples from 144 cancer patients (among which 89\% had ovary or lung malignancies and 94\% received paclitaxel/carboplatin chemotherapy as first-line treatment) were genotyped by LeandroGarcia et al. ${ }^{1}$. In brief, the Infinium BeadChip Human 660WQuad assay (Illumina, San Diego, California, USA) was used and the GenomeStudio software was applied to extract genotype data. One sample with a call rate $<0.95$ was excluded and after filtering 559348 single nucleotide variants (SNVs) were annotated and used in the subsequent association analysis.

Patients' blood status was monitored throughout the treatment and the time to first toxic event (CTCAE grade $\geq 1$ ) was used as the toxicity parameter for thrombocytopenia. Associations of SNVs to thrombocytopenia was assessed with Cox regressions using an additive genetic model adjusted for age in PLINK (version 1.07). A hazard ratio $>1$ indicates that the minor allele is associated with toxicity.

From this study, we used SNVs with P-values $<0.002$ (the same cut-off as we used for our variants) and $M A F \geq 0.01$ for the association to thrombocytopenia $(n=1595)$. The SNVs that we could successfully validate in the presented manuscript are listed in S1 Table.

\section{References}

1. Leandro-García L, Inglada-Pérez L, Pita G, Hjerpe E, Leskelä S, Jara C, et al. Genome-wide association study identifies ephrin type a receptors implicated in paclitaxel induced peripheral sensory neuropathy. Journal of Medical Genetics 2013; 50(9): 599-605. 
Supplementary Table S1. Validated SNVs from the independent GWAS dataset.

\begin{tabular}{ccccccc} 
Chromosome & Position & rsID & Minor allele & MAF & Hazard ratio & P-value \\
\hline 1 & 174209909 & rs12079820 & G & 0,40 & 2,07 & $9,42 E-04$ \\
1 & 174343705 & rs10912773 & A & 0,40 & 2,07 & $9,42 E-04$ \\
6 & 30794617 & rs915664 & G & 0,33 & 0,48 & $7,68 E-04$ \\
6 & 31387557 & rs2596531 & G & 0,39 & 0,54 & $1,84 \mathrm{E}-03$ \\
6 & 31389784 & rs2844511 & A & 0,39 & 0,54 & $1,84 E-03$ \\
6 & 31390410 & rs2516448 & A & 0,39 & 0,54 & $1,84 \mathrm{E}-03$ \\
9 & 753093 & rs7025610 & G & 0,07 & 2,35 & $5,19 E-04$ \\
10 & 96760812 & rs11812285 & C & 0,31 & 2,03 & $8,86 E-05$ \\
10 & 96769769 & rs1934975 & G & 0,30 & 2,01 & $1,68 E-04$ \\
14 & 66147694 & rs2300871 & C & 0,08 & 2,57 & $1,86 E-03$ \\
14 & 94773121 & rs3790036 & G & 0,16 & 1,91 & $1,47 \mathrm{E}-03$ \\
17 & 48290686 & rs2103273 & A & 0,18 & 2,38 & $1,51 \mathrm{E}-04$ \\
21 & 40506615 & rs2142113 & A & 0,50 & 0,59 & $1,42 E-03$ \\
\hline
\end{tabular}

Abbreviations: MAF, minor allele frequency. 


\begin{tabular}{|c|c|c|c|c|c|c|c|c|c|c|c|c|c|c|c|c|}
\hline \multirow{2}{*}{\multicolumn{17}{|c|}{ oplementary Table s2. All PPV }} \\
\hline Chromosome & Position rsID & Ref & Alt & $\begin{array}{l}\text { Type } \\
\text { Type }\end{array}$ & Annotation & Consequence & Gene name & CADD & alue PV2 & beta PV2 & P-value PV4 & beta PV4 MAF Minor allele & Major allele & & & \\
\hline & 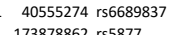 & c & G & SNV & Transcript & 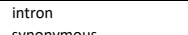 & $\begin{array}{l}\text { PPT1 } \\
\text { CEPPNG1 }\end{array}$ & 2,94 & $1,62 E-03$ & $\begin{array}{c}-0,514 \\
020\end{array}$ & $\begin{array}{r}1,311-03 \\
, 12503\end{array}$ & $-0,5770,071 \mathrm{G}$ & $\begin{array}{c}c \\
\end{array}$ & 2 & 26 & 5 \\
\hline & 1738878862 r55877 & $\mathrm{T}$ & c & SNV & Coding Transcript & & SERPINC1 1 & 0,10 & 1,077-03 & 0,298 & 1,23E-03 & $0,3240,328 \mathrm{c}$ & $\mathrm{T}$ & 24 & 91 & \\
\hline & 247886949 rs36075193 & $\mathrm{T}$ & c & SNV & Transcript & splice, intron, nc & RP11-634B7.5 & 1,06 & $1,12 \mathrm{E}-03$ & 0,413 & $1,40 \mathrm{E}-03$ & $0,4460,142 \mathrm{C}$ & $\mathrm{T}$ & 3 & 54 & 155 \\
\hline & 37468837 rs 17409514 & $\sigma^{\prime}$ & A & SNV & Coding Transcript & synonymous & NDUFAF7 & 10,63 & $1,67 \mathrm{E}-05$ & $-1,575$ & $6,03 E-05$ & $-1,6200,014 \mathrm{~A}$ & 6 & 0 & 6 & 206 \\
\hline & 170063471 rs3551414151 & A & G & SNV & Coding Transcript & synonymous & LRP2 & 1,78 & $5,50 \mathrm{E}-04$ & 0,872 & $1,62 \mathrm{E}-04$ & $1,045 \quad 0,026 \mathrm{G}$ & A & 1 & 9 & 202 \\
\hline & 2. 170097707 rs 177848149 & $\mathrm{~T}$ & ${ }^{\mathrm{G}}$ & SNV & Coding Transcript & missense & LRP2 & 0,76 & $5,50 E-04$ & 0,872 & $1,62 E-04$ & $1,045 \quad 0,026 \mathrm{G}$ & $T^{\top}$ & 1 & 9 & 202 \\
\hline & 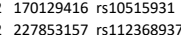 & $\begin{array}{l}c \\
G\end{array}$ & TA & $\begin{array}{l}\text { SNV } \\
\text { SNV }\end{array}$ & $\begin{array}{l}\text { Transcript } \\
\text { Transcript }\end{array}$ & $\begin{array}{l}\text { intron } \\
\text { intron }\end{array}$ & $\begin{array}{l}{ }_{\text {LRP2 }} \\
\text { RHBD1 }\end{array}$ & 2,49 & $\begin{array}{l}9,58 \mathrm{E}-04 \\
5,53 \mathrm{E}-0.5\end{array}$ & $\begin{array}{r}0,866 \\
-1495\end{array}$ & $\begin{array}{l}2,696-04 \\
1,24-03\end{array}$ & $\begin{array}{rl}1,048 & 0,024 \mathrm{~T} \\
-1327 & 0,014 \mathrm{~A}\end{array}$ & $\begin{array}{l}c \\
G\end{array}$ & 1 & ${ }_{6}^{8}$ & 203 \\
\hline & 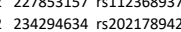 & $\begin{array}{l}\text { GGTGTGGGTGT } \\
\text { G }\end{array}$ & $\begin{array}{l}\text { A } \\
\text { c }\end{array}$ & $\begin{array}{l}\text { SNV } \\
\text { DEL }\end{array}$ & $\begin{array}{l}\text { Transcript } \\
\text { Regulatory Feature }\end{array}$ & $\begin{array}{l}\text { intron } \\
\text { regulatory }\end{array}$ & $\begin{array}{l}\text { RRBDDD1 } \\
\text { DGKD* }\end{array}$ & 6,60 & $\begin{array}{l}5,53 \mathrm{E} \mathrm{E}-05 \\
6,83-\mathrm{C}\end{array}$ & $\begin{array}{l}-1,495 \\
-0,761\end{array}$ & $\begin{array}{l}1,24-\mathrm{E}-03 \\
1,50-03\end{array}-$ & 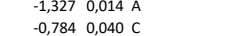 & $\begin{array}{l}\text { GGTGTGCGTGT } \\
\text { CG }\end{array}$ & $\begin{array}{c}0 \\
0 \\
0\end{array}$ & $\begin{array}{c}6 \\
17 \\
\end{array}$ & $\begin{array}{l}206 \\
195 \\
295-P l\end{array}$ \\
\hline & 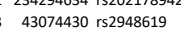 & A & & SNV & $\begin{array}{l}\text { Coding Transcript } \\
\text { Conte }\end{array}$ & $\begin{array}{l}\text { reguatiry } \\
\text { synonymous }\end{array}$ & FAM198A & $\begin{array}{l}0,1 / 4 \\
1,83\end{array}$ & $\begin{array}{l}3,32 \mathrm{E}-04 \\
0.034\end{array}$ & $\begin{array}{l}-0,761 \\
-0,307\end{array}$ & $\begin{array}{l}\begin{array}{l}1,30 E-0.03 \\
3,97 E-04\end{array} \\
3\end{array}$ & $\begin{array}{ll}-0,0784 & 0,040 \mathrm{C} \\
-0,333 & 0,441 \mathrm{~A}\end{array}$ & $\begin{array}{l}\text { CGTGTGCGTGT } \\
\text { G }\end{array}$ & $\begin{array}{c}0 \\
43\end{array}$ & $\begin{array}{c}17 \\
101\end{array}$ & $\begin{array}{r}195 \\
68\end{array}$ \\
\hline & 173997153 rs7646919 & G & A & SNV & $\begin{array}{l}\text { Coding Transcript } \\
\text { Cons }\end{array}$ & synonymous & NLGN1 & 9,90 & $1,67 \mathrm{E}-03$ & $-0,345$ & 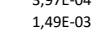 & $\begin{array}{lll}-0,3354 & 0,201 \mathrm{~A}\end{array}$ & G & 8 & 69 & 135 \\
\hline & 40045025 rs 732229741 & $\mathrm{~T}$ & c & $\mathrm{SNV}$ & Non Coding Transcript & non coding exon & RP11-333E13.4 & 1,22 & $1,09 \mathrm{E}-03$ & 0,550 & $7,08 E-04$ & $0,6270,071 \mathrm{C}$ & T & 1 & 28 & 183 \\
\hline & 123192240 r rs45608936 & A & c & $\mathrm{sNV}$ & Coding Transcript & missense & KIAA1109 & 19,99 & $1,50 \mathrm{E}-03$ & $-0,812$ & $1,93 \mathrm{E}-03$ & $\begin{array}{ll}-0,874 & 0,031 \quad C\end{array}$ & A & 0 & 13 & 199 \\
\hline & 14741984 rs22288474 & $\mathrm{T}$ & c & SNV & Coding Transcript & synonymous & ANKH & 3,19 & 1,11E-03 & 0,775 & $5,06 E-04$ & $0,9080,035 \mathrm{C}$ & $\mathrm{T}$ & 0 & 15 & 197 \\
\hline & 161522556 rs111135176 & c & T & SNV & Coding Transcript & synonymous & GABRG2 & 13,74 & $1,17 \mathrm{E}-03$ & 0,464 & $1,75 E-03$ & $0,492 \quad 0,111 \mathrm{~T}$ & c & 1 & 45 & 166 \\
\hline & 25862466 rs 11655165 & c & T & SNV & Coding Transcript & missense & SLC17A3 & 8,30 & $4,76 E-04$ & $-0,353$ & 1,79E-03 & $-0,348 \quad 0,231 \mathrm{~T}$ & c & 12 & 74 & 126 \\
\hline & 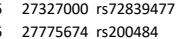 & $\begin{array}{l}C \\
A\end{array}$ & $T_{G}^{T}$ & $\begin{array}{l}\text { SNV } \\
\text { SNV }\end{array}$ & 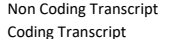 & $\begin{array}{l}\text { non coding exon } \\
\text { missense }\end{array}$ & $\begin{array}{l}\text { ZNFF204P } \\
\text { HISTHHZLL }\end{array}$ & $\begin{array}{r}16,39 \\
2,68\end{array}$ & $\begin{array}{l}2,56 \mathrm{E}-04 \\
1,23-03\end{array}$ & $\begin{array}{l}-0,561 \\
-0,450\end{array}$ & $\begin{array}{l}2,93 \mathrm{E} E-04 \\
1,47-03\end{array}$ & $\begin{array}{ll}-0,61210,0833 \mathrm{~T} \\
-0,488 & 0,104 \mathrm{G}\end{array}$ & $\begin{array}{l}\mathrm{C} \\
\mathrm{A}\end{array}$ & ${ }_{3}^{2}$ & $\begin{array}{l}31 \\
38\end{array}$ & $\begin{array}{l}179 \\
171\end{array}$ \\
\hline & 27835218 rs rs 1776303089 & $\begin{array}{l}A \\
G\end{array}$ & & SNV & Coding Transcript & 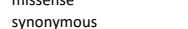 & HISTIH1B & $\begin{array}{l}2,08 \\
6,33\end{array}$ & $\begin{array}{l}1,135-0 \mathrm{~V} \\
6,76 \mathrm{E}-04\end{array}$ & $\begin{array}{l}-0,450 \\
-0,528\end{array}$ & $\begin{array}{l}1,174-0.03 \\
8,21 E-04\end{array}$ & $\begin{array}{ll}-0,488 & 0,0404 \mathrm{G} \\
-0,572 & 0,087 \mathrm{~A}\end{array}$ & $\begin{array}{l}A \\
G\end{array}$ & $\begin{array}{l}3 \\
2\end{array}$ & $\begin{array}{l}38 \\
31\end{array}$ & $\begin{array}{l}171 \\
169\end{array}$ \\
\hline & 27839746 rs200956 & T & c & SNV & Coding Transcript & synonymous & HISTIH3I & 0,01 & $9,46 E-04$ & $-0,418$ & $1,32 \mathrm{E}-03$ & $\begin{array}{llll}-0,447 & 0,125 \mathrm{C}\end{array}$ & T & 5 & 43 & 164 \\
\hline & 27879200 r rs34788973 & c & A & $\mathrm{SNV}$ & Coding Transcript & missense & $\mathrm{OR} 2 \mathrm{~B} 2$ & 22,30 & $2,56 \mathrm{E}-04$ & $-0,561$ & $2,93 E-04$ & $-0,6120,083 \mathrm{~A}$ & c & 2 & 31 & 179 \\
\hline & 27879982 r561742093 & A & G & $\mathrm{SNV}$ & Coding Transcript & missense & OR2B2 & 13,66 & $2,56 \mathrm{E}-04$ & $-0,561$ & $2,93 \mathrm{E}-04$ & $-0,612 \quad 0,083 G$ & A & 2 & 31 & 179 \\
\hline & 28228342 rs1679709 & A & G & SNV & Coding Transcript & missense & NKAPL & 12,58 & $1,09 E-04$ & $-0,476$ & $1,30 \mathrm{E}-04$ & $\begin{array}{ll}-0,518 & 0,118 \mathrm{~A}\end{array}$ & G & 7 & 36 & 169 \\
\hline & 28239915 rs11965538 & G & A & SNV & Non Coding Transcript & non coding exon & 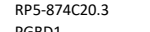 & 1,74 & $9,35 E-05$ & $-0,499$ & $\begin{array}{l}1,10 E-04 \\
205\end{array}$ & $\begin{array}{ll}-0,544 & 0,120 \mathrm{~A}\end{array}$ & G & 6 & 37 & 162 \\
\hline & 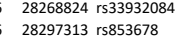 & ${ }_{\mathrm{T}}^{A}$ & ${ }_{A}^{G}$ & $\begin{array}{l}\text { SNV } \\
\text { SNV }\end{array}$ & $\begin{array}{l}\text { Coding TTansscript } \\
\text { Coding Transcript }\end{array}$ & $\begin{array}{l}\text { misssense } \\
\text { missense }\end{array}$ & $\begin{array}{l}\text { PGBD1 } \\
\text { Z5CAN31 }\end{array}$ & $\begin{array}{r}3,91 \\
12,47\end{array}$ & $\begin{array}{l}2,62 \mathrm{E}-04 \\
9,72-04\end{array}$ & $\begin{array}{l}-0,539 \\
-0,416\end{array}$ & $\begin{array}{l}2,59 \mathrm{E}-04 \\
1,20-03\end{array}$ & $\begin{array}{ll}-0,5949,0,092 \mathrm{G} \\
-0.449 & 0,116 \mathrm{~A}\end{array}$ & A & 2 & 35 & 175 \\
\hline & 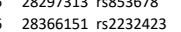 & A & $\begin{array}{l}A \\
G\end{array}$ & $\begin{array}{l}\text { SNV } \\
\text { SNV }\end{array}$ & $\begin{array}{l}\text { Coding Transscript } \\
\text { Coding Transcript }\end{array}$ & $\begin{array}{l}\text { missense } \\
\text { missense }\end{array}$ & $\begin{array}{l}\text { SSCAN31 } \\
\text { ZsCAN12 }\end{array}$ & $\begin{array}{r}12,4 / 4 \\
0,00\end{array}$ & $\begin{array}{l}9,2 / 2-0.04 \\
5,91 E-04\end{array}$ & $\begin{array}{l}-0,416 \\
-0,518\end{array}$ & $\begin{array}{l}1,20 \mathrm{EE}-03 \\
6,30 \mathrm{E}-04\end{array}$ & $\begin{array}{l}-0,45990,116 \mathrm{~A} \\
-0,567 \\
0,087 \mathrm{G}\end{array}$ & A & 2 & 33 & ${ }_{177}^{169}$ \\
\hline & 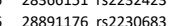 & & $c$ & SNO & Coding Transcrit & S & (T) & 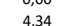 & 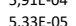 & 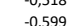 & 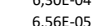 & 作 & $\mathrm{A}_{\mathrm{T}}$ & 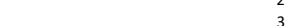 & 30 & 176 \\
\hline 6 & 28963248 rs 54568880 & $\mathrm{~T}$ & G & SNV & Coding Transcript & missense & ZNF311 & 0,39 & $5,24 \mathrm{E}-04$ & 0,282 & $8,70 \mathrm{E}-04$ & $0,2990,453 \mathrm{G}$ & $\mathrm{T}$ & 50 & 30 & 70 \\
\hline 6 & 29342775 rs37499971 & G & A & $\mathrm{SNV}$ & Coding Transcript & missense & OR12D3 & 1,61 & 5,93E- -05 & $-0,586$ & $1,76 E-04$ & $-0,604 \quad 0,094 \mathrm{~A}$ & G & 2 & 36 & 174 \\
\hline 6 & 29523957 rs40424240 & A & G & SNV & Coding Transcript & synonymous & UBD & 3,11 & $2,76 \mathrm{E}-05$ & $-0,616$ & $1,13 \mathrm{E}-04$ & $-0,627 \quad 0,092 G$ & A & 2 & 35 & 175 \\
\hline & 30078275 rs252323989 & c & T & SNV & Coding Transcript & missense & TRIM31 & 0,04 & $5,67 E-04$ & - 0,367 & $1,18 E-03$ & $\begin{array}{ll}-0,381 & 0,184 \mathrm{~T}\end{array}$ & c & 10 & 58 & 144 \\
\hline 6 & 30078330 rs2239529 & c & $T$ & SNV & Coding Transcript & synonymous & TRIM31 & 12,41 & $1,01 E-03$ & $-0,352$ & $1,90 \mathrm{E}-03$ & $-0,367 \quad 0,179 \mathrm{~T}$ & c & 10 & 56 & 146 \\
\hline & 30080274 r 525517598 & G & A & SNV & Coding Transcript & synonymous & TRIM31 & 0,09 & 8,79E-04 $2,-2$ & $-0,354$ & 1,75E-03 & $-0,3680,186 \mathrm{~A}$ & ${ }^{G}$ & 10 & 59 & 143 \\
\hline & 30080496 rss28447933 & G & A & $\begin{array}{l}\text { SNV } \\
\text { SNY }\end{array}$ & Coding Transcript & synonymous & TRIM31 & 9,47 & $1,01 E-03$ & -0,352 & $\begin{array}{l}1,90 E-03 \\
-1,0502\end{array}$ & $\begin{array}{lll}-0,367 & 0,179 \mathrm{~A}\end{array}$ & G & 10 & 56 & 146 \\
\hline & 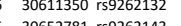 & & A & & Intergenic & $\begin{array}{l}\text { upstream } \\
\text { missense }\end{array}$ & 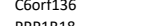 & 9,61 & 6,07E-04 & $-0,445$ & $1,80 \mathrm{E}-03$ & $-0,4470,111 \mathrm{~A}$ & $\mathrm{c}$ & 5 & 37 & 170 \\
\hline & 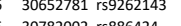 & c & $T$ & $\begin{array}{l}\text { SNV } \\
\text { SNY }\end{array}$ & Coding Transcript & missense & PPIR1R18 & $\begin{array}{l}32,00 \\
\text { S }\end{array}$ & 1,34E-04 & $-0,508$ & 3,644-04 & $-0,5230,009 \mathrm{~T}$ & c & 4 & 38 & 170 \\
\hline & 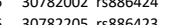 & $c$ & 1 & (a) & Non Coding Iranscript & non coding exon & Linco0 243 & 4,10 & $2,14 t-04$ & -0,496 $>0$ & $1,13 E-03$ & $-0,4900,102$, & $c$ & 4 & 年 & 172 \\
\hline & 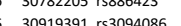 & $a_{0}$ & A & sav & 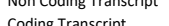 & 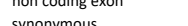 & DPCO1.45 & $\begin{array}{l}2,52 \\
882\end{array}$ & 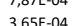 & 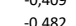 & 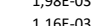 & 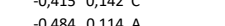 & 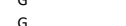 & 3 & 列 & 157 \\
\hline & 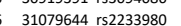 & $G_{G} \rightarrow C_{1}$ & $\hat{A}$ & ${ }_{S N V}$ & $\begin{array}{l}\text { Conding Transcript } \\
\text { Const }\end{array}$ & 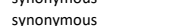 & $\begin{array}{l}\text { Cont15 } \\
\text { Cofits }\end{array}$ & 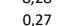 & 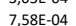 & 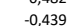 & $\begin{array}{l}1,172-03 \\
1,2-03\end{array}$ & $-0.450 .1113 \mathrm{~A}$ & $G$ & 5 & 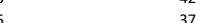 & ${ }_{166}^{166}$ \\
\hline & 311085356 & $c$ & $\mathrm{~T}$ & ${ }_{S N V}$ & $\begin{array}{l}\text { Transcript } \\
\text { Trantint }\end{array}$ & $\begin{array}{l}\text { Sintron } \\
\text { inter }\end{array}$ & CDSN & 6,04 & 3,33E-04 & -0.457 $-2,5$ & $1,07 E_{-03}^{-03}$ & 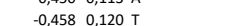 & $c$ & 5 & 41 & 166 \\
\hline & 31236654 rs10499709 & $T_{T}$ & c & sNV & Transcript & 3 prime UTR & HLACC & 5,41 & $5,04 E-04$ & $-0,428$ & $8,34 E-04$ & $\begin{array}{ll}-0,4533 & 0,134 \mathrm{C}\end{array}$ & $T_{T}$ & 5 & 47 & 160 \\
\hline & 31431813 rs3130907 & A & $G$ & SNV & Non Coding Transcript & non coding exon & НСР5 & 5,27 & 3,18E-04 & $-0,443$ & 6,43E-04 & $-0,46330,125 \mathrm{G}$ & A & 7 & 37 & 160 \\
\hline & 31543031 rss800629 & G & A & SNV & Regulatory Feature & regulatory & TNF* & 1,54 & $2,92 \mathrm{E}-04$ & $-0,408$ & 6,63E-04 & $-0,423 \quad 0,186 \mathrm{~A}$ & $G$ & 6 & 67 & 139 \\
\hline & 31603770 rs 111229 & A & G & SNV & Coding Transcript & synonymous & PRRC2A & 5,59 & $8,61 E-04$ & $-0,358$ & $1,92 E-03$ & $\begin{array}{rl}-0,368 & 0,198 \mathrm{G}\end{array}$ & A & 9 & 66 & 137 \\
\hline & $\begin{array}{l}31604591 \text { rs } 10885 \\
3_{13} 17277907\end{array}$ & c & T & $\begin{array}{l}\text { SNV } \\
\text { SNY }\end{array}$ & $\begin{array}{l}\text { Coding Transcript } \\
\end{array}$ & missense & PRRC2A & $\begin{array}{l}24,20 \\
1139\end{array}$ & $8,61 E-04$ & $-0,358$ & $\begin{array}{l}1,92 \mathrm{E}-03 \\
805 \mathrm{~S}\end{array}$ & $\begin{array}{rl}-0,368 & 0,198 \mathrm{~T}\end{array}$ & c & 9 & 66 & 137 \\
\hline & 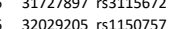 & $\begin{array}{l}c \\
G\end{array}$ & $\begin{array}{l}T \\
A\end{array}$ & $\begin{array}{l}\mathrm{SNV} \\
{ }_{\mathrm{SNV}}\end{array}$ & $\begin{array}{l}\text { Coding Transscript } \\
\text { Coding Transcript }\end{array}$ & $\begin{array}{l}\text { synonnymous } \\
\text { synonymous }\end{array}$ & $\begin{array}{l}\text { MSHF } \\
\text { TNXB }\end{array}$ & $\begin{array}{r}11,39 \\
686\end{array}$ & $\begin{array}{l}3,43 E-04 \\
1,58-04\end{array}$ & $\begin{array}{l}-0,434 \\
-0,539\end{array}$ & $\begin{array}{l}8,16-0.04 \\
7,56--04\end{array}$ & $\begin{array}{l}-0,448 \\
-0,531\end{array} 0,095 \mathrm{~T}$ & $\begin{array}{l}c \\
G\end{array}$ & $\frac{7}{4}$ & 31 & ${ }_{171}^{164}$ \\
\hline & 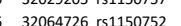 & T & $c_{c}^{A}$ & $\begin{array}{c}\text { sNo } \\
\text { SNy }\end{array}$ & 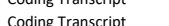 & 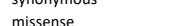 & TNXB & $\begin{array}{l}0,0,00 \\
0,00\end{array}$ & 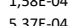 & 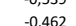 & 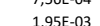 & 作 & T & ${ }_{4}^{4},-5$ & 39 & 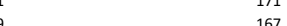 \\
\hline & 32223632 rs3132966 & G & A & $\mathrm{SNV}$ & Non Coding Transcript & non coding exon & XXbac-BPG154L12.4 & 11,37 & $1,52 \mathrm{E}-03$ & -0,311 & $1,93 \mathrm{E}-03$ & $-0,334 \quad 0,257$ A & G & 15 & 79 & 118 \\
\hline & 32230600 r r99268055 & $\mathrm{T}$ & c & sNV & Non Coding Transcript & non coding exon & XXbac-BPG154L12.4 & 0,74 & $8,28 \mathrm{E}-04$ & $-0,329$ & $9,11 E-04$ & $\begin{array}{lll}-0,359 & 0,264 \mathrm{C}\end{array}$ & $T_{T}$ & 15 & 81 & 114 \\
\hline & 32261507 rs37499966 & $\mathrm{T}$ & $c$ & SNV & Coding Transcript & missense & c6or 10 & 0,00 & $4,26 E-04$ & -0,344 & 5,34E-04 & $-0,3720,267 \mathrm{C}$ & & 15 & 83 & 114 \\
\hline & 32270363 rs 57753332 & A & $\mathrm{T}$ & SNV & Transcript & intron & c6orf10 & 0,11 & $3,02 E-04$ & $-0,353$ & $3,72 E-04$ & $\begin{array}{ll}-0,383 & 0,269 \mathrm{~T}\end{array}$ & A & 15 & 84 & 113 \\
\hline & 49479750 rs 13193063 & $\mathrm{~T}$ & c & SNV & Coding Transcript & missense & GLYATL3 & 18,12 & $1,19 \mathrm{E}-03$ & $-0,300$ & $5,01 E-04$ & $\begin{array}{lll}-0,354 & 0,311 \mathrm{C}\end{array}$ & $\mathrm{T}$ & 21 & 90 & 101 \\
\hline & $\begin{array}{l}56426931 \text { rs936767689 } \\
556402701\end{array}$ & c & & $\begin{array}{l}\text { SNV } \\
\text { SNY }\end{array}$ & Transcript & splice, intron & DST & 11,85 & $1,11 E-03$ & 0,292 & $\begin{array}{l}1,73 E-03 \\
1,1503\end{array}$ & $\begin{array}{ll}0,309 & 0,340 \mathrm{~T}\end{array}$ & c & ${ }_{25}^{26}$ & 92 & 94 \\
\hline & 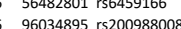 & $\begin{array}{l}\mathrm{C} \\
\mathrm{CTG}\end{array}$ & $\begin{array}{l}G \\
c\end{array}$ & $\begin{array}{l}\text { SNV } \\
\text { DEL }\end{array}$ & $\begin{array}{l}\text { Transcript } \\
\text { Transcript }\end{array}$ & $\begin{array}{l}\text { intron } \\
\text { intron feature truncation }\end{array}$ & $\begin{array}{l}\text { DST } \\
\text { MANEA }\end{array}$ & $\begin{array}{r}15,46 \\
4,46\end{array}$ & $\begin{array}{l}9,40 E-04 \\
1,63-03\end{array}$ & $0,0,298$ & $\begin{array}{l}1,81-1 E-03 \\
5,92-04\end{array}$ & $\begin{array}{l}0,310 \quad 0,335 \mathrm{G} \\
0,534\end{array}$ & ${ }_{C T G}^{c}-1-1$ & ${ }_{4}^{25}$ & ${ }^{92}$ & ${ }_{177}^{95}$ \\
\hline & $1171750008 \mathrm{r} r 69907580$ & ${ }_{G}^{G}$ & $A_{A}$ & ${ }_{S N \mathrm{~N}}$ & $\begin{array}{l}\text { Coding Transcript } \\
\text { Cols }\end{array}$ & 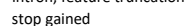 & $\begin{array}{l}\text { NAAVA } \\
\text { GPRCA }\end{array}$ & $\begin{array}{r}4,40 \\
35,00 \\
-1\end{array}$ & $\begin{array}{l}1,03 \mathrm{E}-\mathrm{US} \\
1,80 \mathrm{E}-03\end{array}$ & 0 & $\begin{array}{l}3,52 \mathrm{E}-\mathrm{U} \\
6,41 \mathrm{E}-04\end{array}$ & $0,616 \quad 0,075$ A & $a^{G}$ & 1 & 30 & 181 \\
\hline & $1500002520 \mathrm{rr566246065}$ & A & $G$ & ${ }_{S N V}$ & 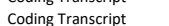 & $\begin{array}{l}\text { spnonymous } \\
\text { synom }\end{array}$ & LATS1 & 1,10 & 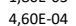 & 1,004 & 7,766-05 & $1,2420,0.024 \mathrm{G}$ & A & 0 & 10 & 202 \\
\hline & o 153365100 r rs2295230 & A & $c$ & SNV & Coding Transcript & synonymous & RGS17 & 0,02 & $5,08 E-04$ & -0,334 & $1,53 \mathrm{E}-03$ & $-0,33550,293 \mathrm{C}$ & A & 17 & 90 & 105 \\
\hline & $\begin{array}{l}1 \\
1\end{array}$ & $G$ & A & SNV & Coding Transcript & missense & FNDC1 & 7,99 & $1,65 \mathrm{E}-03$ & 1,278 & $1,90 \mathrm{E}-04$ & 1,660 $0,012 \mathrm{~A}$ & $G$ & 0 & 5 & 206 \\
\hline & $\begin{array}{l}170845354 \\
r 593488278\end{array}$ & A & G & SNV & Transcript & intron & PSMB1 & 4,67 & $8,91 \mathrm{E}-04$ & 0,284 & $7,44 E-04$ & $0,318 \quad 0,460 \mathrm{G}$ & A & 46 & 103 & 63 \\
\hline & 1708662300 rs 127717 & G & c & SNV & Coding Transcript & missense & PSMB1 & 0,06 & $1,27 E-03$ & 0,278 & 6,42E-04 & $0,324 \quad 0,408 \mathrm{C}$ & $\mathrm{G}$ & 37 & 99 & 76 \\
\hline & 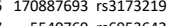 & G & 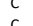 & $\begin{array}{l}\text { SNV } \\
\text { SNY }\end{array}$ & Transcript & intron & 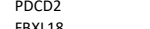 & 0,21 & $8,14 E-04$ & 0,286 & $4,33 E-04$ & $\begin{array}{ll}0,330 & 0,408 \mathrm{C}\end{array}$ & & 势 & ${ }^{97}$ & 77 \\
\hline & 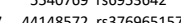 & CTGAG & $c$ & SNV & $\begin{array}{l}\text { Coding Transcript } \\
\text { Intergenic }\end{array}$ & $\begin{array}{l}\text { synonymous } \\
\text { unstream }\end{array}$ & $\begin{array}{l}\text { BEXX18 } \\
\text { MIR4649 }\end{array}$ & $\begin{array}{r}0,00 \\
3300\end{array}$ & $\begin{array}{l}1,43-E=03 \\
7,60-04\end{array}$ & $\begin{array}{l}-0,453 \\
-1,369\end{array}$ & $\begin{array}{l}6,681-04 \\
8,79 E-04\end{array}$ & $\begin{array}{l}-0,530 \\
-1489 \\
-140912 \mathrm{~A}\end{array}$ & CTGAG & $a_{0}^{3}$ & ${ }_{5}^{33}$ & $\begin{array}{l}173 \\
207 \\
207-3\end{array}$ \\
\hline & 44180652 rs444010539 & 6 & $\mathrm{~T}$ & SNV & Coding Transcript & $\begin{array}{l}\text { apssteam } \\
\text { synonymous }\end{array}$ & $\begin{array}{l}\text { MYK } 4049 \\
\text { ML7 }\end{array}$ & $\begin{array}{l}23,200 \\
10,35\end{array}$ & $\begin{array}{l}7,000=04 \\
7,97-04\end{array}$ & 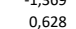 & $\begin{array}{l}8,9=-04 \\
2,68 E-04\end{array}$ & $\begin{array}{rr}-1,489 & 0,012 \\
0,749 & 0,054 \mathrm{~T}\end{array}$ & 6 & 1 & 21 & ${ }_{190}^{207}$ \\
\hline & 149523195 r r & 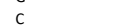 & $G$ & ${ }_{S N V}$ & Non Coding Transcript & $\begin{array}{l}\text { hon coding exon } \\
\text { non coling ex }\end{array}$ & SSPO & $\begin{array}{lll}5,29 \\
5,29\end{array}$ & $1,645-03$ & 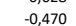 & $\begin{array}{l}1,44 E-03 \\
1,4\end{array}$ & $\begin{array}{l}-0,5240,099 \mathrm{G} \\
-0.096\end{array}$ & $c$ & 1 & 40 & 171 \\
\hline & 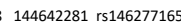 & $c$ & $T$ & sNv & Transcript & intron & GSDMD & 3,86 & $5,18 E-05$ & $-1,028$ & $5,21 E-04$ & $-0,9750,0,31 \mathrm{~T}$ & $c$ & 0 & 13 & 198 \\
\hline & $\begin{array}{l}1 \\
1446428\end{array}$ & 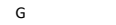 & A & SNV & Coding Transcript & synonymous & GSDMD & 3,53 & $5,97 \mathrm{E}-05$ & - $-1,020$ & $5,92 E-04$ & $-0,96660,031 \mathrm{~A}$ & $G$ & 0 & 13 & 196 \\
\hline & 3) 1446565977 rs 578452615 & G & c & SNV & Regulatory Feature & regulatory & NAPRT * & 2,18 & $5,10 \mathrm{E}-05$ & - $-1,027$ & $5,22 E-04$ & $\begin{array}{lll}-0,973 & 0,031 \mathrm{C}\end{array}$ & $\mathrm{G}$ & 0 & 13 & 199 \\
\hline 0 & 449798 rs 10491684 & $\mathrm{G}$ & ${ }^{A}$ & SNV & 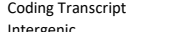 & $\begin{array}{l}\text { synonymous } \\
\text { dewnstream }\end{array}$ & $\begin{array}{l}\text { DOCK8 } \\
\text { RP11-165243 }\end{array}$ & 11,71 & $1,95 E-04$ & -0,627 & $2,12 \mathrm{E}-04$ & $\begin{array}{llll}-0,687 & 0,078 \mathrm{~A}\end{array}$ & ${ }^{6}$ & 0 & 33 & 179 \\
\hline & 449956 rs 12351520 & & 1 & SNV & Intergenic & downstream & RP11-165F24.3 & & 1,95E-04 & -0,627 & 2,12E-04 & $-0,6870,078 \mathrm{~T}$ & c & 0 & 33 & 179 \\
\hline
\end{tabular}




\begin{tabular}{|c|c|c|c|c|c|c|c|c|c|c|c|c|c|c|c|c|}
\hline 9 & 452149 rs16909246 & G & c & SNV & Intergenic & downstream & RP11-165F24.3 & 0,60 & $1,74 \mathrm{E}-03$ & $-0,465$ & $1,59 \mathrm{E}-03$ & $-0,5160,101 \mathrm{C}$ & G & 1 & 41 & 170 \\
\hline & 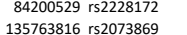 & $\begin{array}{l}T \\
c\end{array}$ & $\begin{array}{l}c \\
\mathrm{~T}\end{array}$ & $\begin{array}{c}\text { SNV } \\
\text { SNY } 20\end{array}$ & $\begin{array}{l}\text { Codidng Transcript } \\
\text { Coding Transcript }\end{array}$ & $\begin{array}{l}\text { synnonymous } \\
\text { synonymous }\end{array}$ & TLE1 & $\begin{array}{l}8,67 \\
662\end{array}$ & $\begin{array}{l}1,94 \mathrm{E}-04 \\
1,2 \mathrm{E}-03\end{array}$ & - $-0,944$ & $\begin{array}{l}1,58 \mathrm{E}-03 \\
87 \mathrm{E}-04\end{array}$ & 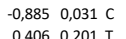 & T & 0 & 13 & ${ }_{199}^{199}$ \\
\hline 10 & 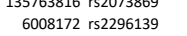 & c & $\mathrm{T}$ & SNV & $\begin{array}{l}\text { Codidgi Iranscript } \\
\text { Coding Transcript }\end{array}$ & $\begin{array}{l}\begin{array}{l}\text { synonymous } \\
\text { synonymous }\end{array} \\
\text { s. }\end{array}$ & $\begin{array}{l}\text { glort9 } \\
\text { ILISRA }\end{array}$ & $\begin{array}{r}6,62 \\
10,86\end{array}$ & $\begin{array}{l}1,2 \mathrm{LE}-03 \\
8,17 \mathrm{E}-04\end{array}$ & $\begin{array}{l}0,358 \\
-0,474\end{array}$ & $\begin{array}{l}8,71 \mathrm{EE}-04 \\
1,59 \mathrm{E}-03\end{array}$ & $\begin{array}{l}0.40600,2011 \mathrm{~T} \\
-0,4933 \\
0,116 \mathrm{~T}\end{array}$ & $c$ & 1 & $\begin{array}{l}11 \\
47\end{array}$ & $\begin{array}{l}134 \\
164\end{array}$ \\
\hline 10 & 15649698 rs93333269 & T & G & SNV & Coding Transcript & missense & ITGAB & 1,13 & $1,46 \mathrm{E}-03$ & 0,478 & $5,92 E-04$ & $0,566 \quad 0,097 \mathrm{G}$ & T & 1 & 39 & 172 \\
\hline 10 & 33214802 rs2298141 & A & G & SNV & Coding Transcript & synonymous & ITGB1 & 5,00 & $7,44 \mathrm{E}-04$ & $-0,402$ & $4,48 E-04$ & $-0,460 \quad 0,156 \mathrm{G}$ & A & 5 & 56 & 151 \\
\hline 10 & 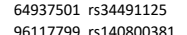 & $\mathrm{G}$ & c & SNV & $\begin{array}{l}\text { Coding Transcript } \\
\text { Trancsirt }\end{array}$ & $\begin{array}{l}\text { missense } \\
\text { jutron }\end{array}$ & JMJD1C & 22,10 & $\begin{array}{r}9,07 E-05 \\
200=-05\end{array}$ & $\begin{array}{l}-1,175 \\
-1,772\end{array}$ & $\begin{array}{l}8,35 E-04 \\
5,0 E-04\end{array}$ & $\begin{array}{lll}-1,109 & 0,021 \mathrm{C}\end{array}$ & G & ${ }^{0}$ & 9 & 203 \\
\hline 10 & $\begin{array}{l}966117799 \text { r rs } 1408000381 \\
96796861 \text { r1 }\end{array}$ & $\begin{array}{l}c \\
G\end{array}$ & ${ }_{A}^{T}$ & 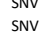 & $\begin{array}{l}\text { Transscript } \\
\text { Transcript }\end{array}$ & $\begin{array}{l}\text { intron } \\
3 \text { prime UTR }\end{array}$ & $\begin{array}{l}\text { NoCCL } \\
\text { CYP2C8 }\end{array}$ & $\begin{array}{l}0,14 \\
1,28\end{array}$ & $\begin{array}{l}2,90 \mathrm{EE}-05 \\
5,87 \mathrm{E}-04\end{array}$ & $\begin{array}{l}-1,672 \\
0,363\end{array}$ & $\begin{array}{l}5,99 \mathrm{EE}-04 \\
4,14 \mathrm{E}-04\end{array}$ & $\begin{array}{rl}-1,5222 & 0,012 \mathrm{~T} \\
0,410 & 0,186 \mathrm{~A}\end{array}$ & ${ }_{G}^{c}$ & $\begin{array}{c}0 \\
11\end{array}$ & $\begin{array}{r}5 \\
57\end{array}$ & 207 \\
\hline 10 & 96827119 rs11572078 & & TA & INS & $\begin{array}{l}\text { Transccipt } \\
\text { Transcript }\end{array}$ & splice, intron, feature elongation & CYP2C8 & $\begin{array}{l}1,100 \\
0,54\end{array}$ & $1,67 \mathrm{E}-04$ & 0,383 & $1,09 \mathrm{E}-04$ & $0,433 \quad 0,208$ TA & T & ${ }_{13}^{13}>{ }_{1}$ & 62 & \\
\hline 10 & 100195130 rs11539873 & $\sigma$ & A & SNV & Coding Transcript & $\begin{array}{l}\text { synonymous } \\
\text { s.atre cing }\end{array}$ & HPS1 & 4,39 & $1,45 \mathrm{E}-03$ & $-0,565$ & $1,29 \mathrm{E}-03$ & $\begin{array}{lll}-0,628 & 0.068 \mathrm{~A}\end{array}$ & $\mathrm{G}$ & 0 & 29 & ${ }_{183}^{183}$ \\
\hline 10 & 127504998 rs17153575 & c & $\mathrm{T}$ & SNV & Transcript & splice, intron & UROS & 14,66 & $2,10 \mathrm{E}-05$ & -1,693 & $9,266-04$ & ${ }_{-1,463}^{-0,012 \mathrm{~T}}$ & $c$ & 0 & 5 & 207 \\
\hline 11 & 6578792 rs112656142 & $\mathrm{T}$ & c & SNV & Coding Transcript & missense & DNHD1 & 0,00 & $1,51 \mathrm{E}-03$ & 1,166 & $2,45 E-04$ & $1,4780,014 \mathrm{C}$ & T & 0 & 6 & 206 \\
\hline 11 & 6584806 rs734007197 & G & A & SNV & Regulatory Feature & regulatory & DNHD1* & 10,63 & $1,51 \mathrm{E}-03$ & 1,166 & $2,45 E-04$ & $1,4780,014 \mathrm{~A}$ & G & 0 & 6 & 206 \\
\hline 11 & $\begin{array}{l}6588256 \text { rs } 1242189976 \\
65591280\end{array}$ & $G$ & A & SNV & Coding Transcript & synonymous & DNHD1 & 0,37 & $1,51 \mathrm{E}-03$ & 1,166 & $2,45 E-04$ & $1,478 \quad 0,014 \mathrm{~A}$ & G & 0 & 6 & 206 \\
\hline${ }_{11}^{11}$ & 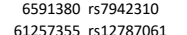 & $G_{G}^{G}$ & c & $\begin{array}{c}\text { SNV } \\
\text { SNV }\end{array}$ & $\begin{array}{l}\text { Transcript } \\
\text { Coding Transcript }\end{array}$ & $\begin{array}{l}\text { intron } \\
\text { missense }\end{array}$ & $\begin{array}{l}\text { DNND1 } \\
\text { PPP11232 }\end{array}$ & $\begin{array}{l}0,62 \\
0,00\end{array}$ & $\begin{array}{l}1,51 \mathrm{E}-03 \\
18 \mathrm{E}-04\end{array}$ & $\begin{array}{l}1,166 \\
-0,710\end{array}$ & $\begin{array}{l}2,45 E-04 \\
171 E-04\end{array}$ & $\begin{array}{lll}1,478 & 0,014 \mathrm{C}\end{array}$ & G & ${ }^{0}$ & 6 & 206 \\
\hline $\begin{array}{l}11 \\
11 \\
1\end{array}$ & $\begin{array}{l}612537355 \text { r r } 121787061 \\
71850130 \text { r } 61734430\end{array}$ & $\begin{array}{l}G \\
c\end{array}$ & $\begin{array}{l}\mathrm{c} \\
\mathrm{T}\end{array}$ & 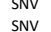 & $\begin{array}{l}\text { Coding Iranscrirt } \\
\text { Coding Transcript }\end{array}$ & $\begin{array}{l}\begin{array}{l}\text { missnense } \\
\text { synonymous }\end{array} \\
\text { s. }\end{array}$ & $\begin{array}{l}\text { PPP1R32 } \\
\text { FOLR3 }\end{array}$ & $\begin{array}{r}0,00 \\
11,70\end{array}$ & $\begin{array}{l}1,86 E-04 \\
9,91 E-04\end{array}$ & $\begin{array}{l}-0,0170 \\
-0,776\end{array}$ & $\begin{array}{l}1,77 \mathrm{EE}-04 \\
6,97 \mathrm{E}-04\end{array}$ & $\begin{array}{ll}-0,0866 & 0,052 \mathrm{C} \\
-0,879 & 0,031 \mathrm{~T}\end{array}$ & ${ }_{c}^{G}$ & $\begin{array}{l}1 \\
1\end{array}$ & $\begin{array}{l}20 \\
11\end{array}$ & 191 \\
\hline 11 & 108384207 rs2846412 & c & & SNV & Coding Transcript & missense & EXPH5 & 0,00 & $7,65 \mathrm{E}-04$ & 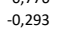 & $6,66 E-04$ & $\begin{array}{lll}-0,326 & 0,484 \mathrm{~T}\end{array}$ & & 49 & ${ }_{107}$ & $\begin{array}{r}199 \\
56\end{array}$ \\
\hline 11 & $11789962011: 117899620$ & & c & DEL & Transcript & intron, feature truncation & TMPBSSA-AS1 & 5,40 & $1,05 E-04$ & -1,557 & $1,74 E-03$ & $-1,39220,012 \mathrm{C}$ & CAGG & 0 & 5 & $\begin{array}{r}56 \\
207\end{array}$ \\
\hline 11 & 129722553 rs558813 & c & $\mathrm{T}$ & SNV & Coding Transcript & missense, splice & TMEM45B & 0,00 & $1,94 \mathrm{E}-03$ & -0,329 & $1,566-03$ & $\begin{array}{lll}-0,3699 & 0,196 \mathrm{~T}\end{array}$ & $c$ & 10 & 63 & 139 \\
\hline 12 & 95228286 rs2289030 & G & c & SNV & Non Coding Transcript & non coding exon & MIR492 & 1,35 & $1,15 \mathrm{E}-03$ & $-0,531$ & $6,68 \mathrm{E}-04$ & $-0,6110,078 \mathrm{C}$ & G & 1 & 31 & 180 \\
\hline 13 & 78216915 rs2813739 & c & $\mathrm{T}$ & SNV & Coding Transcript & synonymous & SCEL & 12,69 & $1,82 \mathrm{E}-03$ & $-0,352$ & $1,04 \mathrm{E}-03$ & $-0,4070,165 \mathrm{~T}$ & c & 8 & 54 & 150 \\
\hline 14 & 65878847 rs34007703 & $T^{T}$ & ${ }^{T G}$ & INS & Regulatory Feature & regulatory & FUT8* & 10,28 & $1,41 \mathrm{E}-03$ & 0,768 & $2,47 E-04$ & $0,967 \quad 0,035$ TG & T & 0 & 15 & 197 \\
\hline${ }_{14}^{14}$ & $\begin{array}{l}75279395 \text { rs232302834 } \\
77991034 \text { rs61755559 }\end{array}$ & T & ${ }_{G}^{A}$ & $\begin{array}{c}\text { SNV } \\
\text { SNV }\end{array}$ & $\begin{array}{l}\text { Coding Transcript } \\
\text { Transcript }\end{array}$ & $\begin{array}{l}\text { synonymous } \\
\text { splice intron }\end{array}$ & $\begin{array}{l}\text { YLPM1 } \\
\text { AHSAA }\end{array}$ & $\begin{array}{l}9,74 \\
5,32\end{array}$ & $\begin{array}{r}6,74 E-04 \\
-6505\end{array}$ & - $-0,314$ & $1,03 E-03$ & $\begin{array}{lll}-0,334 & 0,361 \mathrm{~T}\end{array}$ & A & 25 & ${ }^{103}$ & ${ }^{84}$ \\
\hline${ }_{14}^{14}$ & $\begin{array}{l}793031034 \text { r r615155659 } \\
95053849 \text { rs6113 }\end{array}$ & $\begin{array}{c}{ }^{A} \\
T\end{array}$ & $\begin{array}{l}G \\
c\end{array}$ & $\begin{array}{l}\text { SNV } \\
\text { SNV }\end{array}$ & $\begin{array}{l}\text { Transccript } \\
\text { Coding Transcript }\end{array}$ & $\begin{array}{l}\text { Splice, intron } \\
\text { synonymous }\end{array}$ & $\begin{array}{l}\text { AHSAA } \\
\text { SERPINAS }\end{array}$ & $\begin{array}{l}5,32 \\
0,01\end{array}$ & $\begin{array}{l}4,66 \mathrm{E}-05 \\
1,36 \mathrm{E}-03\end{array}$ & $\begin{array}{l}-1,487 \\
-0,458 \\
-10\end{array}$ & $\begin{array}{l}6,42 E-04 \\
1,67 E-03\end{array}$ & $\begin{array}{ll}-1,3300,014 & 0,0 \\
-0,503 & 0,106 \mathrm{C}\end{array}$ & ${ }_{T}^{A}$ & $\begin{array}{l}0 \\
1\end{array}$ & $\begin{array}{r}6 \\
43\end{array}$ & $\begin{array}{l}206 \\
{ }_{168}\end{array}$ \\
\hline 14 & $95053863 \mathrm{rs} 6118$ & c & & SNV & Coding Transcript & $\begin{array}{l}\text { myissense } \\
\text { mistous }\end{array}$ & $\begin{array}{l}\text { SERRINAS } \\
\text { SERPINAS }\end{array}$ & $\begin{array}{r}0,01 \\
22,30\end{array}$ & $\begin{array}{l}1,05 \mathrm{E}-\mathrm{U}-\mathrm{s} \\
5,83 \mathrm{E}\end{array}$ & $\begin{array}{l}-0,458 \\
-0,483\end{array}$ & $\begin{array}{l}1,06 \mathrm{E}-03 \\
7,02 \mathrm{E}-04\end{array}$ & $\begin{array}{lll}-0,524 & 0,110 \mathrm{~T}\end{array}$ & & $\frac{1}{2}$ & 42 & $\begin{array}{l}168 \\
166\end{array}$ \\
\hline 14 & 95054012 rs6119 & A & G & SNV & Coding Transcript & missense & SERPINAS & 0,00 & $6,13 \mathrm{E}-04$ & -0,506 & $6,677-04$ & $\begin{array}{lll}-0,553 & 0,102 \mathrm{G}\end{array}$ & A & 1 & 41 & $\begin{array}{l}100 \\
169\end{array}$ \\
\hline 15 & 42154738 rs16972193 & G & A & SNV & Coding Transcript & missense, splice & SPTBN5 & 21,90 & $1,466-04$ & $-0,461$ & $6,75 E-04$ & $-0,455 \quad 0,137 \mathrm{~A}$ & $\mathrm{G}$ & 7 & 42 & 155 \\
\hline 16 & 5122072 rs112683515 & G & GGTCT & INs & Regulatory Feature & regulatory & AlG1* & 7,46 & $1,066-03$ & $-0,290$ & $1,73 \mathrm{E}-03$ & $-0,306 \quad 0,453 \mathrm{G}$ & GGTCT & 42 & 108 & 62 \\
\hline 16 & 56686470 rs12051311 & c & $\mathrm{T}$ & SNV & Intergenic & downstream & MT1CP & 0,75 & $9,24 \mathrm{E}-04$ & $-0,287$ & $7,59 \mathrm{E}-04$ & $-0,3200,493 \mathrm{C}$ & T & 52 & 105 & 55 \\
\hline 17 & 6115 rs61739713 & $\mathrm{G}$ & c & SNV & Coding Transcript & $\begin{array}{l}\text { synonymous } \\
\text { sypompous }\end{array}$ & DOC2B & 9,04 & $4,20 \mathrm{E}-04$ & $-0,344$ & $1,09 E-03$ & $\begin{array}{ll}-0,352 \quad 0,224 \mathrm{G} \\
\end{array}$ & c & 15 & 65 & 132 \\
\hline${ }_{17}^{17}$ & 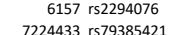 & A & ${ }_{\mathrm{G}}^{\mathrm{T}}$ & $\begin{array}{c}\text { SNV } \\
\text { SNV }\end{array}$ & $\begin{array}{l}\text { Coding Transcript } \\
\text { Codidng Transcript }\end{array}$ & $\begin{array}{l}\text { synonymous } \\
\text { missense splice }\end{array}$ & $\begin{array}{l}\text { DOE2B } \\
\text { NERI4 }\end{array}$ & $\begin{array}{r}0,02 \\
01,52\end{array}$ & $\begin{array}{l}4,79 E-04 \\
205 E-04\end{array}$ & $\begin{array}{l}-0,337 \\
--_{2,272} \quad l\end{array}$ & $1,18 \mathrm{E}-03$ & $\begin{array}{lll}-0,345 & 0,226 \mathrm{~A}\end{array}$ & G & 16 & 64 & 132 \\
\hline 17 & $\begin{array}{l}72244333 \text { r r7993855421 } \\
8064779 \text { r } 775664430\end{array}$ & $\begin{array}{l}c \\
c\end{array}$ & $\begin{array}{l}T \\
G\end{array}$ & 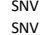 & $\begin{array}{l}\text { Codidng Transcript } \\
\text { Intergenic }\end{array}$ & 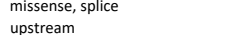 & $\begin{array}{l}\text { NEERLA } \\
\text { PER1 }\end{array}$ & $\begin{array}{r}15,42 \\
0,32\end{array}$ & $\begin{array}{l}2,005 E-04 \\
1,06 E-03\end{array}$ & $\begin{array}{l}-1,272 \\
-0,352 \\
\text { L }\end{array}$ & $\begin{array}{l}3,91 \mathrm{E}-04 \\
1,92 \mathrm{E}-03\end{array}$ & $\begin{array}{ll}-1,3,300,0,017 & \mathrm{~T} \\
-0,367 & 0,252 \\
\mathrm{G}\end{array}$ & $\begin{array}{l}c \\
c\end{array}$ & $\begin{array}{l}0 \\
8\end{array}$ & 91 & $\begin{array}{l}204 \\
113\end{array}$ \\
\hline 17 & 48437456 rs6504649 & c & G & SNV & Coding Transcript & $\begin{array}{l}\text { mpisterim } \\
\text { missense }\end{array}$ & $\begin{array}{l}\text { XPK1 } \\
\text { XYLT2 }\end{array}$ & $\begin{array}{l}0,02 \\
6,18\end{array}$ & $\begin{array}{l}1,0 \mathrm{OE}-\mathrm{C}-\mathrm{S} \\
1,25 \mathrm{E}\end{array}$ & $\begin{array}{l}-0,052 \\
-0,311\end{array}$ & $\begin{array}{l}1,9 \mathrm{EE}-\mathrm{US} \\
1,73 \mathrm{E}-03\end{array}$ & $\begin{array}{ll}-0,3018 & 0,370 \mathrm{G} \\
-0,3370 & 0,0\end{array}$ & c & 21 & 115 & $\begin{array}{r}113 \\
76\end{array}$ \\
\hline 17 & 56395757 rs2072147 & c & $\mathrm{T}$ & SNV & Coding Transcript & missense & BZRAP1 & 17,08 & $3,38 \mathrm{E}-04$ & . & $8,12 \mathrm{E}-04$ & $-1,0140,026 \mathrm{~T}$ & c & 0 & 11 & 201 \\
\hline 17 & $56396609 \mathrm{r}$ rs2072145 & T & c & SNV & Coding Transcript & missense & BZRAP1 & 9,23 & $3,38 \mathrm{E}-04$ & $-0,984$ & $8,12 \mathrm{E}-04$ & $-1,014 \quad 0,026 \mathrm{C}$ & $\mathrm{T}$ & 0 & & 201 \\
\hline 18 & 29432624 rs37373774 & $\mathrm{T}$ & c & SNV & Coding Transcript & missense, splice & TRAPPCB & 11,20 & $5,84 \mathrm{E}-04$ & 0,329 & $3,08 E-04$ & $0,3800,366 \mathrm{C}$ & $\mathrm{T}$ & 22 & 111 & 79 \\
\hline 18 & 34647322 rs72890602 & G & $\mathrm{T}$ & SNV & Coding Transcript & missense & KIAA1328 & 0,46 & $5,16 \mathrm{E}-04$ & $-0,732$ & $1,27 \mathrm{E}-03$ & $-0,749 \quad 0,040 \mathrm{~T}$ & G & 1 & 15 & 196 \\
\hline 19 & $\begin{array}{r}7831628 \text { rs22277998 } \\
0\end{array}$ & $\mathrm{G}$ & A & SNV & Coding Transcript & $\begin{array}{l}\text { missense } \\
\text { micsence }\end{array}$ & CLECAM & 0,01 & $1,85 \mathrm{E}-03$ & $-0,274$ & $1,44 \mathrm{E}-03$ & $\begin{array}{lll}-0,308 & 0,347 \mathrm{~A}\end{array}$ & G & 29 & 89 & 94 \\
\hline 19 & $\begin{array}{l}104446603 \text { rs22230399 } \\
10543727 \text { rs } 39275433\end{array}$ & 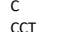 & G & SNV & $\begin{array}{l}\text { Coding Transcript } \\
\text { Regulatory Feature }\end{array}$ & $\begin{array}{l}\text { misssense } \\
\text { resulatery }\end{array}$ & $\begin{array}{l}\text { ICAM3 } \\
\text { PDEA* }\end{array}$ & $\begin{array}{r}4,28 \\
10,02\end{array}$ & $\begin{array}{l}1,05 E-03 \\
85 E-04\end{array}$ & $\begin{array}{l}-0,565 \\
-0,505\end{array}$ & $6,02 E-04$ & $\begin{array}{ll}-0,650 & 0,073 \mathrm{G}\end{array}$ & $c$ & 0 & 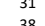 & 181 \\
\hline 19 & $\begin{array}{l}10543272 \text { r r } 1332775533 \\
35633601 \text { r } 149407483\end{array}$ & ${ }_{c}^{\mathrm{CCT}}-\mathrm{r}-\mathrm{a}$ & $\begin{array}{l}\mathrm{c} \\
\mathrm{T}\end{array}$ & $\begin{array}{l}\text { DEL } \\
\text { SNV }\end{array}$ & $\begin{array}{l}\text { Regulatory Feature } \\
\text { Regulatory Feature }\end{array}$ & $\begin{array}{l}\text { regulatory } \\
\text { regulatory }\end{array}$ & $\begin{array}{l}\text { PDEA4* } \\
\text { FXYD1* }\end{array}$ & $\begin{array}{l}10,02 \\
15,73\end{array}$ & $\begin{array}{l}8,5 \mathrm{SE}-04 \\
2,07 \mathrm{E}-05\end{array}$ & $\begin{array}{l}-0,005 \\
-1,700\end{array}$ & $\begin{array}{l}6,99 E-04 \\
1,07 E-03\end{array}$ & $\begin{array}{ll}-0,565 & 0,094 \mathrm{C} \\
-1,450 & 0,012 \mathrm{~T}\end{array}$ & ${ }_{c}^{\mathrm{cct}}$ & $0_{0}^{1}$ & ${ }_{5}^{30}$ & $\begin{array}{l}173 \\
207\end{array}$ \\
\hline 19 & $46269313 \mathrm{rs} 2014377$ & G & c & $\begin{array}{l}\text { SNV } \\
\text { SNV }\end{array}$ & $\begin{array}{l}\text { Regulatory Feature } \\
\text { Coding Transcript }\end{array}$ & $\begin{array}{l}\text { missense } \\
\text { mity }\end{array}$ & SIXS & $\begin{array}{r}15,1 / 3 \\
0,09\end{array}$ & $\begin{array}{l}8,87 \mathrm{E}-04 \\
8,04\end{array}$ & $\begin{array}{l}-1,100 \\
0,362\end{array}$ & $\begin{array}{l}1,0 \mathrm{VE}-\mathrm{US} \\
3,92 \mathrm{E}\end{array}$ & $\begin{array}{ll}1-450,425 & 0,195 \mathrm{G} \\
0,40\end{array}$ & $c$ & 9 & 63 & $\begin{array}{l}207 \\
136\end{array}$ \\
\hline 19 & 58945962 rs9941466 & $c$ & T & SNV & Coding Transcript & synonymous & ZNF132 & 10,29 & $1,10 \mathrm{E}-03$ & $0 ., 533$ & $8,65 E-04$ & $0,5990,078 \mathrm{C}$ & $\mathrm{T}^{\mathrm{N}} \mathrm{l}$ & 1 & 31 & $\begin{array}{l}130 \\
180\end{array}$ \\
\hline 21 & 40177325 rs 57450548 & $G$ & A & SNV & Regulatory Feature & regulatory & ETS2* & 8,83 & $1,27 \mathrm{E}-03$ & $-0,479$ & $1,92 \mathrm{E}-03$ & $-0,5080,099 \mathrm{~A}$ & $\mathrm{G}$ & 1 & 40 & 171 \\
\hline 22 & 19165216 rs28546442 & ${ }^{G}$ & A & SNV & Regulatory Feature & regulatory & SILC2SA1* & 7,23 & 1,266- -03 & $-0,625$ & $8,311-04$ & $-0,712 \quad 0,050 \mathrm{~A}$ & G & 1 & 19 & 191 \\
\hline 22 & 19183787 rs 1633399 & A & G & SNV & Coding Transcript & missense & CLTCL1 & 15,45 & $1,65 \mathrm{E}-03$ & $-0,636$ & $1,27 \mathrm{E}-03$ & $-0,7160,045 \mathrm{G}$ & A & 1 & 17 & 194 \\
\hline 22 & 19195680 irs807547 & $\mathrm{T}$ & c & SNV & Coding Transcript & missense & CLTCL1 & 6,37 & $1,18 \mathrm{E}-03$ & $-0,641$ & 8,77E-04 & $-0,7230,047 \mathrm{C}$ & T & 1 & 18 & 193 \\
\hline 2 & $\begin{array}{l}19197949 \text { rs7712952 } \\
10202325\end{array}$ & G & A & $\begin{array}{c}\text { SNV } \\
\text { SNY }\end{array}$ & Coding Transcript & $\begin{array}{l}\text { missense } \\
\text { micsense }\end{array}$ & CLTCL1 & 32,00 & $1,18 \mathrm{E}-03$ & -0,641 -0411 & $8,77 E-04$ & $-0,72320,047$ A A & 6 & 1 & 18 & 193 \\
\hline 22 & 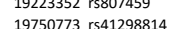 & $T$ & $\begin{array}{l}c \\
c\end{array}$ & 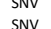 & $\begin{array}{l}\text { Coding Transcript } \\
\text { Coding Transcrit }\end{array}$ & $\begin{array}{l}\text { missense } \\
\text { synonymous }\end{array}$ & ${ }_{\mathrm{TBX} 1}^{\mathrm{CT}}$ & $\begin{array}{r}21,50 \\
5,51\end{array}$ & $\begin{array}{l}1,18 \mathrm{EE}-03 \\
13 \mathrm{E}-03\end{array}$ & $\begin{array}{l}-0,641 \\
0,354\end{array}$ & $\begin{array}{l}8,77 E-04 \\
165 E-03\end{array}$ & $\begin{array}{rl}-0,723 & 0,047 \mathrm{C} \\
0.382 & 0,224 \mathrm{C}\end{array}$ & T & 1 & 10 & ${ }_{124}^{193}$ \\
\hline$x_{x}$ & 85233820 rs 145707160 & $\mathrm{~T}$ & A & SNV & Coding Transcript & $\begin{array}{l}\text { sylonymous } \\
\text { missense }\end{array}$ & CHM & $\begin{array}{r}5,31 \\
23,30\end{array}$ & $5,69 \mathrm{E}-04$ & $\begin{array}{l}0,354 \\
-1,168\end{array}$ & $\begin{array}{l}1,00 \mathrm{E}-\mathrm{US} \\
1,10 \mathrm{E}-03\end{array}$ & $\begin{array}{ll}0,382 & 0,024 \mathrm{~A}\end{array}$ & $\mathrm{~T}$ & 0 & 7 & $\begin{array}{l}124 \\
105\end{array}$ \\
\hline & $\begin{array}{l}114541027 \mathrm{rs} 22232736 \\
1036\end{array}$ & A & 6 & ${ }_{S N V}$ & $\begin{array}{l}\text { Coding Transcript } \\
\text { Cons }\end{array}$ & synonymous & LUZP4 & 0,07 & $1,53 \mathrm{E}-03$ & 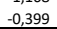 & $\begin{array}{l}1,78 \mathrm{E}-03 \\
-1\end{array}$ & $-0,4330,125 \mathrm{G}$ & A & 1 & 26 & 85 \\
\hline
\end{tabular}


Supplementary Table S3. All PPGs (genes with P-values < 0.002 for both PV2 and PV4). Gene-based association test results for thrombocytopenia using SKATO, adjusted for age and gender.

\begin{tabular}{|c|c|c|c|c|c|}
\hline Chromosome & Gene name & PV2 P-value & PV4 P-value & Number of variants & Variants in gene \\
\hline 1 & SERPINC1 & $1,55 \mathrm{E}-03$ & $1,75 \mathrm{E}-03$ & 5 & rs5878; rs5877; rs2227627; rs121909551; rs2227624 \\
\hline 2 & DGKD & $6,63 \mathrm{E}-04$ & $1,44 \mathrm{E}-03$ & 8 & $\begin{array}{l}\text { 2:234344534; rs2305541; rs148025402; rs10208953; rs2228937; } \\
\text { rs61739478; rs147134923; rs2228939 }\end{array}$ \\
\hline 2 & NDUFAF7 & $7,58 \mathrm{E}-04$ & $1,83 \mathrm{E}-03$ & 4 & rs145277736; rs72875762; rs201231332; rs17409514 \\
\hline 2 & BIN1 & $9,19 E-04$ & $1,45 \mathrm{E}-03$ & 13 & rs375004668; rs138047593; rs61748155; 2:127811494; 2:127811592; \\
\hline 6 & TRIM27 & $6,77 E-05$ & $7,86 \mathrm{E}-05$ & 4 & $\begin{array}{l}\text { rs2276579; rs371258305; rs2228955; rs114833236; rs61748157; } \\
\text { rs41270608; 6:28887823; rs143463783; rs2230683 }\end{array}$ \\
\hline 6 & ZSCAN26 & $1,28 \mathrm{E}-04$ & $1,39 \mathrm{E}-04$ & 6 & $\begin{array}{l}\text { rs76463649; rs16893892; rs11965538; rs11965542; rs187327081; } \\
6: 28244225\end{array}$ \\
\hline 6 & RGS17 & $2,12 \mathrm{E}-04$ & $7,13 \mathrm{E}-04$ & 2 & rs2295230; rs41292882 \\
\hline 6 & OR2B2 & $2,73 \mathrm{E}-04$ & $2,92 \mathrm{E}-04$ & 5 & rs73392698; rs34788973; rs34957169; rs9368537; rs61742093 \\
\hline 6 & SLC17A3 & $4,02 \mathrm{E}-04$ & $1,41 \mathrm{E}-03$ & 3 & rs942379; rs56027330; rs1165165 \\
\hline 6 & PPP1R18 & 4,29E-04 & $8,90 \mathrm{E}-04$ & 5 & rs140243582; 6:30652729; rs9262143; 6:30652787; rs2269706 \\
\hline 6 & DST & $4,68 \mathrm{E}-04$ & $1,20 \mathrm{E}-03$ & 45 & $\begin{array}{l}\text { rs11758339; rs144012429; rs201429821; 6:56334944; rs201115435; } \\
\text { 6:56347530; rs187652380; 6:56362724; rs41271862; rs41271864; } \\
\text { 6:56399939; rs4715630; rs4715631; 6:56417837; rs62621210; } \\
\text { rs11756977; rs9367689; rs9464393; 6:56437548; rs375624981; } \\
\text { rs201249286; rs4712138; rs150191284; rs112473525; rs115542549; } \\
\text { rs115983672; rs6459166; rs141573097; rs12209266; 6:56483348; } \\
\text { rs45487998; rs2230862; rs35497571; rs41271870; rs112640831; } \\
\text { 6:56504813; rs2144407; rs151271595; rs113432929; rs1024196; } \\
\text { rs41267673; rs16888128; rs182517599; rs11969595; rs150003298 }\end{array}$ \\
\hline 6 & ATAT1 & $5,04 \mathrm{E}-04$ & $1,36 \mathrm{E}-03$ & 6 & $\begin{array}{l}\text { 6:30594726; rs146271858; rs6904236; 6:30610668; rs150614928; } \\
\text { rs9262132 }\end{array}$ \\
\hline 6 & OR5V1 & $5,98 \mathrm{E}-04$ & $6,94 \mathrm{E}-04$ & 9 & $\begin{array}{l}\text { rs9257769; rs141436521; rs41271546; rs3117438; rs61742983; } \\
\text { rs7761746; rs28359952; rs9257770; rs6930033 }\end{array}$ \\
\hline 6 & TRIM31 & $6,46 \mathrm{E}-04$ & $1,22 \mathrm{E}-03$ & 24 & $\begin{array}{l}\text { rs1116221; 6:30071354; rs17194258; rs146885411; 6:30071391; } \\
\text { rs3132679; rs2023472; rs28400887; rs62624473; rs115893523; } \\
\text { rs35775852; rs2523989; rs2239529; rs34801993; rs151255204; } \\
\text { rs3734838; 6:30080265; rs2517598; rs35521684; rs34704616; } \\
\text { rs143020056; 6:30080425; rs2844793; rs36063651 }\end{array}$ \\
\hline 6 & PSMB1 & 1,07E-03 & $6,78 \mathrm{E}-04$ & 3 & rs150833808; rs12717; rs10946279 \\
\hline 6 & KIF6 & $1,65 \mathrm{E}-03$ & $7,41 \mathrm{E}-04$ & 12 & $\begin{array}{l}\text { 6:39311549; rs139582255; 6:39314286; rs20455; rs61748649; } \\
\text { rs2273063; 6:39512404; rs7738892; 6:39580978; rs371477997; } \\
\text { rs147204228; rs34016507 }\end{array}$ \\
\hline 6 & ZNF311 & $9,84 \mathrm{E}-04$ & $1,54 \mathrm{E}-03$ & 4 & rs6456880; rs150648543; rs61751894; rs138000372 \\
\hline 6 & NKAPL & $1,38 \mathrm{E}-03$ & $1,56 \mathrm{E}-03$ & 9 & $\begin{array}{l}\text { rs144553865; rs12000; rs1635; rs9461446; 6:28227824; rs3734564; } \\
\text { rs147161729; rs201104720; rs1679709 }\end{array}$ \\
\hline 7 & MYL7 & $9,38 \mathrm{E}-04$ & $3,39 E-04$ & 4 & rs141852636; rs117678382; 7:44180361; rs4440539 \\
\hline 7 & CAPZA2 & 4,03E-04 & $4,21 \mathrm{E}-04$ & 3 & rs374052696; 7:116502628; rs4808 \\
\hline 9 & SPACA9 & $1,40 \mathrm{E}-03$ & $1,02 \mathrm{E}-03$ & 3 & 9:135762918; 9:135763786; rs2073869 \\
\hline 10 & CYP2C8 & $6,47 E-04$ & $4,18 \mathrm{E}-04$ & 11 & $\begin{array}{l}\text { rs1058932; rs10509681; rs77147096; rs369479818; rs11188150; } \\
\text { rs1058930; rs72558195; rs41286886; rs11572080; rs11572079; } \\
\text { rs11572078 }\end{array}$ \\
\hline 11 & TMEM45B & $4,52 \mathrm{E}-04$ & 4,07E-04 & 3 & rs145128105; rs558813; rs78733006 \\
\hline 17 & $\mathrm{DOC} 2 \mathrm{~B}$ & $5,20 \mathrm{E}-04$ & $1,24 \mathrm{E}-03$ & 3 & 17:6052; rs61739713; rs2294076 \\
\hline$x$ & $\mathrm{CHM}$ & $1,86 \mathrm{E}-05$ & $9,31 \mathrm{E}-05$ & 2 & $X: 85119740 ;$ rs145707160 \\
\hline
\end{tabular}


Supplementary Table S4. Variants included in the wGRS.

\begin{tabular}{lcc} 
rsID & Minor allele & Beta for minor allel \\
\hline rs34491125 & C & $-1,175$ \\
rs10491684 & A & $-0,627$ \\
rs374052696 & T & $-1,376$ \\
$7: 116502628$ & T & $-0,691$ \\
rs4808 & T & $-0,331$ \\
$6: 39311549$ & A & 0,186 \\
rs139582255 & T & $-0,537$ \\
$6: 39314286$ & T & 0,777 \\
rs20455 & G & $-0,223$ \\
rs61748649 & T & 0,053 \\
rs2273063 & T & $-0,412$ \\
$6: 39512404$ & G & $-0,907$ \\
rs7738892 & T & $-0,304$ \\
$6: 39580978$ & T & $-1,264$ \\
rs371477997 & A & $-1,407$ \\
rs147204228 & T & $-0,445$ \\
rs34016507 & C & $-0,743$ \\
\hline Abbreitions: WGRS, weight
\end{tabular}

Abbreviations: wGRS, weighted genetic risk scores. 
Supplementary Table S5. Coefficients for the logistic regression models for the prediction of thrombocytopenia CTCAE and the decrease of platelets.

\begin{tabular}{lcc}
\multicolumn{1}{c}{ Model parameter } & CTCAE model & Decrease model \\
\hline Intercept & -65.5410027 & -88.2483325 \\
rs34491125 & -0.4571852 & -0.1265447 \\
rs10491684 & -17.5645283 & 0.0 \\
rs374052696 & -18.8444645 & -36.8763664 \\
7:116502628 & 0.3548092 & 0.3386908 \\
rs4808 & -0.6392537 & -1.5352321 \\
6:39311549 & 0.6752039 & 1.3721170 \\
rs139582255 & 18.0025217 & 19.3322908 \\
6:39314286 & 0.7531436 & 0.9941634 \\
rs20455 & 18.5022042 & 19.8485981 \\
rs61748649 & 18.9005386 & 20.5040707 \\
rs2273063 & 17.0164587 & 0.0 \\
6:39512404 & 1.8267082 & 16.1535803 \\
rs7738892 & 18.2075950 & 19.7504007 \\
6:39580978 & 1.3866380 & 2.4464639 \\
rs371477997 & 1.1194446 & 1.1507203 \\
rs147204228 & 0.9345956 & 1.3543144 \\
rs34016507 & 3.3224846 & 20.9256816 \\
\hline Abbrevitions: CTCAE & common terminology
\end{tabular}

Abbreviations: CTCAE, common terminology criteria for adverse events. 